\title{
Representaciones del conflicto armado y la paz en procesos alter comunicativos del sur de Colombia
}

$\mathrm{E}$ n este capítulo se propone un marco de análisis posible, para interpretar el conflicto social y armado que vive Colombia, desde los procesos alter comunicativos e informativos desarrollados por experiencias cuyo trabajo se inscribe en zonas de conflicto armado, es decir, en zonas donde existe presencia de actores armados (institucionales, para estatales y no institucionales) que ejecutan acciones armadas que afectan a la población civil, la infraestructura del país y el sistema de relaciones que configuran los procesos de sociabilidad local.

Para el caso colombiano, el conflicto armado es de carácter no internacional (interno). Según señala en Comité Internacional de la Cruz Roja (CICR), este es un tipo de conflicto "entre fuerzas gubernamentales y grupos armados no gubernamentales, o entre esos grupos únicamente. El derecho de los tratados de DIH (...) hace una distinción entre conflictos armados no internacionales en el sentido del artículo 3 común a los Convenios de Ginebra de 1949 y conflictos armados no internacionales, según la definición contenida en el artículo 1 del Protocolo adicional II.” (CICR, 2008, p.1) En este sentido, y según el Artículo 1 del Protocolo adicional II al Convenio de Ginebra, el conflicto armado interno (no internacional) es aquel que, 
se desarrolla en el territorio de una Alta Parte Contratante entre sus fuerzas armadas y fuerzas armadas disidentes o grupos armados organizados que, bajo la dirección de un mando responsable, ejerzan sobre una parte de dicho territorio un control tal que les permita realizar operaciones militares sostenidas y concertadas... (CICR, 2008, p.4)

En lo que refiere a la categoría de actor(es) $\operatorname{armado(s),~la~entendemos~}$ aquí desde dos perspectivas: la primera corresponde a los actores armados no estatales / no institucionales, aquellos que,

(...) primero, tienen la capacidad y voluntad de usar la violencia para conseguir sus objetivos; y segundo, no están integrados en instituciones estatales tales como los ejércitos regulares, guardias presidenciales o fuerzas especiales, aunque pueden ser apoyados por estos de manera formal o informal. (Schneckener citado por Laborie, 2011, p.43)

Según la Guía de las Naciones Unidas para las negociaciones humanitarias con grupos armados, estos actores armados no estatales:

(...) tienen el potencial de emplear armas en el uso de la fuerza para alcanzar objetivos políticos, ideológicos o económicos; no están dentro de las estructuras militares formales de los Estados, alianzas entre Estados u organizaciones intergubernamentales; y no son controlados por el Estado o Estados en que operan. (Laborie, 2011, p.43)

En segundo lugar encontramos a los actores armados estatales / institucionales. Estos son cuerpos militares y, para el caso de Colombia, de policía, que ven delimitadas sus acciones por los marcos legales y normativos establecidos en la Constitución Nacional: "La fuerza pública estará integrada en forma exclusiva por las Fuerzas Militares y la Policía Nacional.” (Artículo 216 de la Constitución Política de Colombia). Las Fuerzas Militares tienen como finalidad primordial: "la defensa de la soberanía, la independencia, la integridad del territorio 
nacional y del orden constitucional" (Artículo 217 de la Constitución Política de Colombia), mientras que la Policía Nacional tiene como fin "el mantenimiento de las condiciones necesarias para el ejercicio de los derechos y libertades públicas, y para asegurar que los habitantes de Colombia convivan en paz" (Artículo 218 de la Constitución Política de Colombia).

Esta categorización de los actores armados permite entender que las circunstancias propias del conflicto armado formulan unos contextos particulares de acercamiento, análisis y producción de contenidos informativos, a los productores de alter medios que desarrollan sus actividades comunicativas "en medio de las balas". Lo que se señala es que las circunstancias y los contextos alter comunicativos ${ }^{1}$ que se despliegan en las zonas de conflicto armado difieren, en gran medida, de las condiciones de producción informativa de los centros urbanos, donde la presencia e incidencia directa de los actores armados (representada en la acción armada: enfrentamientos, masacres, asesinatos, etc.) se evidencia con menor intensidad, sobre todo si se tiene en cuenta que, como se señala en el informe Basta ya, memorias de guerra y dignidad, del Centro Nacional de Memoria Histórica de Colombia (CNMH):

Ver la violencia desde la perspectiva de la tierra y los territorios revela otro rasgo distintivo de su historia: la guerra se ha librado mayoritariamente en el campo colombiano, en los caseríos, veredas y municipios, lejanos y apartados del país central o de las grandes ciudades. Es una guerra que muchos colombianos y colombianas no ven, no sienten, una guerra que no los amenaza. Una guerra de la que se tiene noticia a través del lente de los medios de comunicación, que sufren otros y que permite a miles

1 Alter comunicación, en tanto noción, reúne aquel tipo de experiencias desarrolladas en paralelo a las lógicas, estructuras y contextos constitutivos del régimen comunicativo hegemónico. En este sentido, busca reunir en una sola denominación a aquellas otras que han hecho parte del debate y la acción comunicativa subalterna, popular, ciudadana, alternativa y comunitaria. (Ortiz, 2014, 23) 
de personas vivir en la ilusión de que el país goza de democracia plena y prosperidad, a la vez que les impide entender la suma importancia de cada decisión, afirmación o negociación política para quienes la sufren. Quienes viven lejos de los campos donde se realizan las acciones de los armados ignoran que, por ejemplo, un acuerdo que pacte un cese al fuego representa para esos campesinos y campesinas la diferencia entre quedarse o huir, entre vivir o morir. (CNMH, 2013a, p.22)

Es en este contexto que proponemos una serie de elementos para el análisis de los procesos, experiencias y contextos de incidencia de los alter medios que desarrollan sus labores en zonas de conflicto, buscando establecer los sistemas de representación que sobre el conflicto armado y la paz se han formulado desde estas experiencias, en los entornos locales.

Esta perspectiva de análisis implica una reflexión sobre la esfera público-política local, sobre los sistemas de participación y sobre la democracia comunicativa, cuestiones que se expresan desde los actores y procesos de medios alternativos, comunitarios y populares que "viven, sufren y cuentan" la paz y el conflicto estructural que se ha tomado sus territorios, sus prácticas sociopolíticas, sus economías y su cultura, así como sus formas de pensar, producir y circular contenidos.

\section{Alter comunicación y conflicto}

En su Informe sobre la situación de la prensa en Colombia 2013, la Fundación para la Libertad de Prensa (FLIP) señala que:

Las consecuencias de esta guerra para las libertades informativas son imposibles de medir: el $57 \%$ de los asesinatos contra la prensa [SIC] son atribuibles a actores del conflicto, dentro de los que se encuentran paramilitares, guerrillas, fuerza pública y narcotraficantes. (...) Esto, junto a la intimidación de miles de periodistas por 
sus publicaciones, son apenas tímidos indicadores de las múltiples historias que nunca pudieron ser contadas gracias al temor instaurado por la violencia y que aún ronda por buena parte del territorio nacional como una atmósfera de censura. (FLIP, 2013, p.22)

Buena parte de "esas historias que no pudieron ser contadas" tienen como actor principal a los alter medios de comunicación que trabajan en zonas de conflicto armado en Colombia. Estas experiencias atienden a un contexto particular que incide en las lógicas y los procesos de producción informativa, en lo relacionado con los temas del conflicto, la guerra y la paz. Este contexto obliga a los productores de alter medios a establecer estrategias particulares para la producción (o re-producción) de contenidos sobre los asuntos relativos a la guerra y a la paz, lo que nos lleva a preguntarnos por la manera como estas experiencias han configurado representaciones sociales en torno a estos temas, de qué manera se han establecido y qué posibilidades de acción discursiva (de participación en la construcción política de lo público comunicativo) tienen los alter medios que desarrollan su labor en zonas de conflicto.

Las dinámicas del conflicto armado en Colombia son tan complejas y profundas, que han obligado a los alter comunicadores a establecer estrategias comunicativas que les posibiliten, en la medida de lo posible, atender las necesidades informativas de sus comunidades, aplicando muchas veces a sus labores acciones de autocensura. En otros casos, la censura directa de los actores armados obliga a medios y periodistas a dispersar la atención y la acción periodística hacia otros temas que denominaríamos como de menor importancia: "La violencia empleada durante años contra medios de comunicación impone ahora un rotundo silencio informativo en la región. En la radio las noticias son reemplazadas por música y los periódicos se llenan con reinas de bellezas y reyes vallenatos...”, comenta Jonathan Bock en su artículo Las noticias se extinguen en el Bajo Cauca. (2013).

Hay casos en los que los periodistas, frente a la dificultad de producir contenidos directamente relacionados con el conflicto armado y la paz, construyen agendas paralelas donde de manera indirecta tratan temas que se consideran como fuente o "fermento" del conflicto armado y social (las "causas objetivas de la violencia”): “...Conocer 
la verdad de lo que ocurre en él [las regiones apartadas del país] es prácticamente imposible, solo existen verdades y mentiras a medias, precisamente por el silencio de la prensa, hoy acallada después de años de violencia en su contra" (Bock, 2013).

La restricción de los escenarios comunicativos en las zonas de conflicto han llevado a que las experiencias de alter medios atiendan a unas lógicas de producción y de cubrimiento informativo diferentes a las establecidas por los medios masivos hegemónicos de comunicación, en donde a partir de la estandarización noticiosa se instala un discurso en el que: "iTanto dura una masacre de campesinos como un suceso de farándula, pues en la economía del tiempo [mass mediático] valen lo mismo! Extraña economía la de la información, según la cual su costo en tiempo implica que la información, como la actualidad, dure cada vez menos" (Martín Barbero, 2000).

De esta manera se ve como las dinámicas del conflicto impactan en la información. Pero hay que reconocer que las dinámicas de la información también intervienen en las lógicas del conflicto y, sobre todo, en el conocimiento que la opinión pública puede llegar a hacerse del conflicto mismo, por cuanto los medios instituyen socialmente los referentes simbólicos que posibilitan (o no) entender los contextos y dinámicas en los que se desenvuelve la acción bélica:

Se reconoce que hay muchos temas que los periodistas evitan cubrir. (...) Igualmente, prefieren tener cuidado con los temas judiciales por el peligro que implica hablar de las capturas hechas por la Policía ya que se puede estar mencionando a un miembro de los grupos ilegales actuales y recibir represalias por ello. (FLIP, 2012)

Ahora, el impacto del conflicto en las agendas mediáticas es difícil de establecer y de medir, sobre todo en unos contextos en que los mismos medios de comunicación demeritan las consecuencias que el conflicto trae a su propio ejercicio informativo, consecuencias que, por efectos del impacto que generan en las agendas informativas y, por extensión, en la misma opinión pública, deberían ser tema de debate público.

Las "represalias" que los actores armados ejercen sobre los alter medios hacen evidente lo fundamental de la acción comunicativa 
que se despliega desde el escenario mediático, en tanto los medios de comunicación se han venido consolidando como espacios que posibilitan y fortalecen lugares sociales de encuentro (y, por supuesto, de des-encuentro) para los ciudadanos, convirtiéndose en "lugares centrales de la vida social y la imaginación de las prácticas políticas contemporáneas, y siendo a su vez un campo especialmente tensionado de intereses” (Rey, 2003, pp.2-3).

Es así como en este escenario de profundas restricciones, prohibiciones y reservas informativas, son múltiples las respuestas de los alter comunicadores a las imposiciones de la guerra sobre el ejercicio comunicativo, respuestas que han reconfigurado los modos como se define la inclusión o exclusión, en las agendas mediáticas locales, de contenidos relacionados con el conflicto y la paz, así como las contribuciones que hacen estos medios en la construcción política de las esferas públicas locales.

Desde este ángulo, las múltiples experiencias comunicativas que se vienen gestando en medio del conflicto social y armado por parte de la ciudadanía, evidencian la emergencia en la gestión y agenciamiento de otros espacios y lógicas mass mediáticas desde el ámbito comunitario y popular, en consecuencia con la marcada tendencia global en la búsqueda de la participación ciudadana como reivindicación frente a las posibilidades de intervención directa de los sujetos sociales en la construcción colectiva de la esfera pública, por lo que se busca poner en cuestión aquella relación dada entre los medios de comunicación como actores del conflicto, el marco de la guerra y la construcción política de lo público, para problematizar las incidencias que el manejo de la información, su producción discursiva, su distribución y apropiación social tienen sobre las comunidades, ya que, como lo expresó la Alianza de Medios y Periodistas por la Paz en el marco del Paro Nacional Agrario y Popular (2013):

Pareciese que los medios masivos de comunicación ven otra realidad. Como una constante, se presentan noticias en las que se recalca sobre bloqueos de vías, policías heridos y poca participación. (...) Lo que está pasando en los puntos de concentración no está siendo reportado e informado por los medios masivos... (...) 
Resulta preocupante que los medios masivos disfracen la realidad con un manto de tranquilidad cuando lo que está pasando hoy en Colombia también es producto de la indignación que produce ese tipo de desinformación. (Prensa Rural, 2013)

La crisis de los medios masivos de comunicación se inserta, entonces, en un contexto de carácter estructural, sistémico; y al ser sistémico, está interconectado con otros elementos de la estructura social. Por ello, las acciones de los grandes medios de información están ligadas con la macro estructura económica, financiera y política mundial, al punto que las corporaciones mediáticas multinacionales hoy se constituyen en un factor dominante de poder simbólico y material. Como lo señala Pascual Serrano: "los medios de comunicación no son un compartimento estanco ni un sector de producción independiente. No debemos olvidar que sus accionistas, directa o indirectamente, son empresas de telecomunicaciones, grupos bancarios, aseguradoras o constructoras." (Serrano, 2010, pp.9-10)

Esta crisis de régimen comunicativo hegemónico representa, a su vez, la crisis de las sociedades occidentales en lo que refiere a la defensa de la esfera pública, de la res-pública, lo que permite recordar, como se señaló en el Primer Foro de Alternativas Comunicativas², que:

lo público, como construcción social colectiva, está en crisis. Esto porque los ámbitos formales reguladores del espacio común, el Estado y el mercado, ya no significan, representan ni interpretan lo social en su complejidad, en tanto han dejado de ser espacios que agencian la construcción de intereses comunes y, al contrario, han sido dispuestos para el fortalecimiento de la esfera privada y para el posicionamiento de aquellos sectores de poder que administran la res pública. (Proyecto CEIS, 2011) ${ }^{3}$

2 Realizado por el Proyecto CEIS (Colectivo de Estudios e Investigación Social) con el objetivo de acercar a estudiantes a los debates subalternos que sobre los medios, la comunicación y el periodismo se han venido configurando desde las ciudadanías en Colombia.

3 Para ampliar la reflexión sobre este planteamiento se puede ver: Pécaut (2001). 
En respuesta a este escenario, se han venido proponiendo espacios alternativos que desde la ciudadanía, constituyen nuevos-otros ámbitos para el agenciamiento de la esfera pública desde una perspectiva político-mediática, donde:

una de las expresiones ciudadanas que con fuerza se ha venido posicionando en el debate público ha sido la de los medios de comunicación comunitarios, esos que en contrapeso a los medios masivos hegemónicos de información (que funcionan de manera más evidente bajo lógicas estatistas, de comercialización e instrumentalización del discurso social), podrían formular otros escenarios de encuentro para el debate político de las cuestiones públicas. (Proyecto CEIS, 2011)

Así, la alter comunicación funciona en la lógica de las "nuevas ciudadanías" o "ciudadanías emergentes" (Lechner, 2000), en la medida que plantea otros enfoques comunicativos de análisis e intervención ciudadana en el debate social. Esto lleva a pensar en un "descentramiento" de la construcción política de lo público, por lo que se hace necesario reconocer nuevos planos del debate sobre, por ejemplo, el cubrimiento informativo del proceso de negociación de la paz en Colombia, a fin de establecer de qué manera comunidades y procesos alter comunicativos organizados vienen contribuyendo en la reflexión de los temas relacionados con la paz y el conflicto, en la reflexión sobre cómo se viene construyendo simbólicamente la paz y la guerra en los medios de comunicación.

Esto porque hoy las voces ciudadanas organizadas en torno a procesos comunicativos e informativos, están cuestionando asuntos que tienen que ver con temas de diverso tipo: desde la concentración en la propiedad de los medios hasta la democracia formal que se instituye, en sus referentes simbólicos, desde dispositivos como los medios de información. Cuestionan también a las clases dirigentes por su indiferencia social y por haber cooptado las instituciones públicas para ponerlas al servicio de los oligopolios políticos y económicos, al aparato estatal por su ineficacia, a la izquierda democrática por su parálisis, el 
bloqueo histórico de la participación política y hasta la nimia participación del ciudadano en lo referente a la definición de la política social. ${ }^{4}$

Los medios como instituciones tradicionalmente proveedoras de información acerca de la "realidad nacional", han ido perdiendo su jerarquía, capacidad y legitimidad en la conducción social, por cuanto la información que por ellos circula se ha ido "empobreciendo", perdiendo así su carácter referencial para grandes conjuntos de población, aunque sigan, de manera importante y en perspectiva hegemónica, lo que incide en la configuración de la opinión pública nacional.

\section{Representaciones sociales, conflicto (armado) y paz}

En marzo de 2014 una profesora de la Universidad Pedagógica Nacional estaba preocupada porque dos de sus estudiantes le habían manifestado su iniciativa de ir hasta San Vicente del Caguán, en el departamento del Caquetá, al sur de Colombia, para indagar sobre "el impacto que tuvieron en la población civil los diálogos de paz de El Caguán" 5 . Cuando la profesora les preguntó sobre la "logística” que habían preparado para su viaje, las estudiantes respondieron que se iban sin conocer a nadie y sin saber a dónde llegar, y que el motivo de comentarle sobre la propuesta era, precisamente, lograr algunos contactos de personas que las pudieran recibir y acompañar en su "trabajo de campo", en vista de que otros estudiantes les habían

4 Una síntesis de estos presupuestos, desde una mirada política, se puede ver en el documento: Estado y política en Colombia, de Francisco Leal Buitrago (1984). Capítulo: Perspectivas Hacia el Siglo xxi. El Estado Colombiano: ¿Crisis de Modernización o Modernización Incompleta?

5 “El Caguán, como se le conoce popularmente a este proceso, es tal vez el más famoso intento de paz que hayan realizado la guerrilla de las Farc-EP y el gobierno colombiano. Se desarrolló desde 1998 hasta 2002, teniendo como principal escenario una zona de despeje comprendida por los municipios de Mesetas, La Uribe, La Macarena, Villahermosa y San Vicente del Caguán, con una dimensión de 47.000 kilómetros cuadrados” (Indepaz, 2013). 
comentado que la profesora tenía trabajo en la zona y que podría ayudarles con algún "contacto".

La preocupación inicial de la profesora tenía que ver con varias cuestiones, entre ellas una fundamental: estas chicas no sabían para dónde iban, no conocían lo que sucede en esta zona del país, no sabían del peligro al que se podían enfrentar. Este caso, como muchos otros, se puede interpretar como un problema relacionado con la representación que los medios de comunicación han hecho del conflicto armado en Colombia, pues las estudiantes desconocían el contexto de la zona a la que pretendían llegar, los actores que por allí circulan y los acontecimientos (muchos de ellos dramáticos, por decir lo menos) que han constituido la historia de este territorio.

Lo que podía suceder con las estudiantes, en ese momento de preocupación inicial, era similar a lo que le sucedió a dos estudiantes de la Universidad de los Andes en enero de 2011:

Los mataron. A los jóvenes estudiantes de la Universidad de los Andes, Mateo Matamala Neme, de 26 años, y a su novia, la también estudiante de la misma universidad, Margarita Gómez [los mataron]. (...) Lo que no sabían los jóvenes y las personas que les recomendaron desprevenidamente viajar a Montería, Lorica y llegar a San Bernardo [del Viento], es que en este país los sitios paradisiacos siguen en poder de actores ilegales, o se los disputan. (...) Quizás si Margarita o Mateo hubieran escuchado hablar del joven artista cordobés asesinado semanas antes de su llegada, o de los campesinos baleados en los caminos, o de los asesinatos que se multiplican en Córdoba y Sucre, departamentos a los que les pertenece el Golfo de Morrosquillo, quizás hubieran desistido del viaje. (Contravía, 2011)

Lo que se evidenciaba en este caso, al decir que el problema que se presentaba era fundamentalmente de representación mass mediática, es que los medios de comunicación no están contando, a profundidad y con rigor, lo que sucede en el marco del conflicto armado en Colombia, lo que nos lleva a indagar sobre cómo se representan en las agendas alter mediáticas, los temas relacionados con el conflicto armado en 
Colombia, y cuáles son los contextos que permiten establecer los criterios para definir las informaciones que sobre el conflicto armado se distribuyen socialmente por los medios.

En el marco de las acciones estratégicas desplegadas por los medios de comunicación a la hora de tratar información referente al conflicto armado, se han determinado, por efectos de su práctica, una serie de tensiones que obligan a pensar sobre los intereses que subyacen a la información, dando cuenta no solo del proceso informativo mass mediático, teniendo en cuenta factores de carácter político, económico, cultural, ideológico, social y tecnológico. Lo que hay que entender aquí, como se señalara en la Declaración de Cochabamba ${ }^{6}$, es que:

En la transición desde las resistencias frente al neoliberalismo a las ofensivas contra ese modelo, el papel de los medios es trascendental. Por ello, hoy más que nunca nos manifestamos contra el poder sin control, no democrático e impune de los grandes medios de comunicación que intentan imponer su visión de la realidad y sus valores. Estos oligopolios sirven a intereses económicos y políticos de accionistas, financiadores y anunciantes. (2007)

Vemos cómo se instala, en una misma proclama, la relación, hoy obvia, entre los medios de comunicación y sectores (y actores) sociales del tipo económico y político, lo que da a entender que, en el escenario de estas inter dependencias, la información mass mediática que se distribuye cotidianamente (y, por extensión, buena parte de la información que se comparte interpersonalmente, que depende de manera sustancial de las agendas mediáticas) se ve "intervenida" por intereses y disposiciones que, en principio, no le corresponderían.

Hay que establecer, entonces, cómo se revela, se da sentido y significado al discurso informativo que relaciona temas propios del conflicto armado. Lo que se nos plantea es una discusión sobre las

6 Dada en el marco del V Encuentro de Intelectuales y Artistas en Defensa de la Humanidad Realizado en Cochabamba, Bolivia. 22 y 23 de mayo de 2007. 
intenciones del sujeto-institución que informa, una discusión sobre la capacidad que tiene el sujeto-institución de "administrar" el lenguaje en el marco de unos propósitos, cuestión que nos podría llevar a establecer una nueva relación: aquella dada entre la comunicacióninformación y el poder. Manuel Castells ha dicho, frente a esta relación, que una de las grandes fuentes de poder en la Sociedad Red es "la capacidad de programación de las redes", es decir, el potencial que adquieren unos actores sociales específicos para dar orden a los procesos de interacción social:

Esta capacidad depende en última instancia de la posibilidad de generar, difundir y poner en práctica los discursos que enmarcan la acción humana. (...) [Y] los discursos en nuestra sociedad moldean la mente a través de una tecnología concreta: las redes de comunicación que organizan la comunicación socializada. Puesto que la mente pública —es decir, el conjunto de valores y marcos que tienen una gran visibilidad en la sociedad- es en último término lo que influye en el comportamiento individual y colectivo, la programación de las redes de comunicación es la fuente decisiva de los materiales culturales que alimentan los objetivos programados de cualquier otra red. (2010, p.85)

La mirada de Castells sobre la comunicación y el poder, sin ser novedosa en su diagnóstico ${ }^{7}$ aunque sí en los referentes sobre la sociedad actual (que denomina como Sociedad Red), reafirma uno de los presupuestos de nuestra investigación: los medios de comunicación formulan, desde la implementación de sistemas de representación, marcos de interpretación sobre las realidades dadas y sobre las posibles, es decir, semantizan la realidad, la sobre-significan.

Frente a este escenario, y entendiendo que todo poder genera una resistencia, la alter comunicación y los alter medios se presentan como alternativa a la "programación hegemónica" de la sociedad. Por

7 Ver: Mattelart y Dorfman (1972); Mattelart (1974); Serrano (2009), y Chomsky y Ramonet (1995). 
sentado está que reconociendo a estos otros actores que intervienen en los procesos de configuración de las realidades sociales, se reconoce también que los sistemas de relaciones a partir de los cuales se configura la esfera pública social (para este caso, desde los discursos y prácticas mass mediáticas) son múltiples, complejos, problemáticos.

Consideramos que estas cuestiones son sustantivas, por cuanto establecerlas y ponerlas en discusión pública posibilita identificar cómo la sociedad colombiana construye e interpreta, desde una perspectiva local, el conflicto, sus características, sus condicionantes, sus dimensiones, sus actores. Esto porque los medios de comunicación se entienden socialmente como instituciones / dispositivos desde los cuales se delimitan, determinan y debaten los problemas y necesidades públicas y, desde allí, la sociedad recoge los elementos a partir de los cuales puede percibir "el contexto de las relaciones sociales en las que se procesa la comunicación y la información" que posibilita la acción social de los ciudadanos (Castells, 2010).

De lo que se trata es de explorar los sistemas de representaciones que configuran los actores de la alter comunicación en zonas de conflicto, para establecer si, como en el caso de la comunicación masiva hegemónica, desde estos espacios ciudadanos se ha venido negando o no la discusión pública sobre algunos aspectos sustanciales del conflicto armado y, por extensión, sobre la paz y sobre la necesidad de la promoción y defensa de los derechos humanos en Colombia. Se trata, en este sentido, de examinar cómo los factores, lógicas y contextos propios del conflicto armado inciden en los procesos comunicativos locales, y cómo estos contextos limitan la posibilidad social y política de los ciudadanos para dimensionar "objetivamente" las lógicas de la guerra y las oportunidades para la paz.

Aquí la representación funciona como

un sistema de interpretación de la realidad que rige las relaciones de los individuos con su entorno físico y social, ya que determinará sus comportamientos o sus prácticas. [La representación] es una guía para la acción, [por cuanto] orienta las acciones y las relaciones sociales. Es un sistema de pre-decodificación de la realidad, 
puesto que determina un conjunto de anticipaciones y expectativas. (Abric, 1994, p.13)

Los procesos de representación de la guerra y de la paz en los alter medios que actúan en zonas de conflicto llevan a indagar por la forma en que los medios encarnan un modo particular de ver, un punto de vista sobre las realidades sociales, por lo que hay que entrar a comprender el papel que juegan hoy en los procesos de representación social mass mediática, donde se revelan escalas de valores y propósitos específicos de carácter social, político, económico, cultural e ideológico, en la medida en que han sido conformadas por sujetos que se identifican con ciertos modos de actuar y de producir contenidos, en contextos específicos, por cuanto:

La identificación de la ‘visión del mundo' que los individuos o grupos llevan en sí y utilizan para actuar o tomar posición es reconocida como indispensable para entender la dinámica de las interacciones sociales y aclarar los determinantes de las prácticas sociales. (Abric, 1994, p.11)

Este enfoque permite un abordaje conceptual de las representaciones sociales en un doble sentido: posibilita indagar cómo participan los alter medios en el procesamiento "lógico" de la información, al tiempo que devela que la relevancia de lo que se quiere conocer no es intrínseca solo a la información, sino que allí también participan otras cuestiones propias del entorno particular con el que el sujeto interactúa, cuestiones como las intencionalidades informativas de los actores armados, la dimensión e impacto del conflicto armado sobre la sociedad civil y sobre los alter medios, presiones de actores armados en la definición de contenidos, etc., para el caso de este estudio.

Ahora, un abordaje de la alter comunicación en zonas de conflicto desde el escenario de las representaciones, posibilita trazados para una pragmática general que permita establecer los condicionantes, materiales y simbólicos, a partir de los cuales los alter medios pueden llegar a intervenir en la definición de otras representaciones que las comunidades hacen de sus prácticas sociales, culturales, políticas y 
de memoria en medio del conflicto armado, a fin de determinar cómo estos medios intervienen (o no) en la constitución de sujetos políticos y discursos, incidentes en la transformación de la esfera pública local-territorial.

\section{Representaciones alter comunicativas del conflicto armado}

Miremos ahora cómo se representa desde los actores de la alter comunicación vinculados a las experiencias estudiadas, la noción de conflicto armado. Los discursos que sirven como referentes de análisis para establecer el sistema de representaciones sobre la noción señalada, son los testimonios de los gestores de las experiencias alter comunicativas Ocaina estéreo, Piamonte estéreo e Ingakuna estéreo.

Para el caso colombiano, el conflicto armado ha generado intensos debates, no solo en lo que refiere a su trámite militar, sino también a su definición e interpretación, por cuanto estos escenarios de enunciación simbólica definen, en buena medida, las políticas públicas que en materia de seguridad serán aplicadas para la atención de los fenómenos producidos en el escenario del conflicto colombiano.

En el marco de esta polisemia se pueden señalar, de manera general, dos posturas que se han posicionado en el debate público colombiano en los últimos 15 años. La primera, agenciada públicamente desde el gobierno del ex presidente Álvaro Uribe Vélez en el marco de su Política de seguridad democrática, formula la no existencia de una situación de conflicto armado interno en Colombia. En palabras del ex alto comisionado para la paz del gobierno Uribe, Luis Carlos Restrepo ${ }^{8}$ :

- Conflicto armado interno es el término contemporáneo que se utiliza para designar una situación de guerra civil. No es el

8 Comisionado de Paz del gobierno de Álvaro Uribe Vélez entre los años 2002 y 2009. En la actualidad se encuentra prófugo de la justicia, que lo acusa de ser haber promovido y organizado la desmovilización de un falso frente de las FARC-EP (El frente Cacica la Gaitana). Por este hecho existe en la actualidad una orden de captura internacional en su contra. Se encuentra prófugo de la justicia. 
caso de Colombia. Aquí no podemos hablar de enfrentamiento de dos sectores de la población que dirimen sus diferencias por las armas...

- Tampoco existe en Colombia una dictadura personalizada o una constricción constitucional que impida el ejercicio de los derechos fundamentales...

- De allí la premisa central que invoca este gobierno: en Colombia no existe un conflicto armado interno sino una amenaza terrorista. No se trata de un cambio caprichoso en los términos. Es un asunto conceptual de vital importancia para el destino de la Nación...

- Lo que no podemos hacer es reconocer a los terroristas derecho para atacar a nuestros policías y soldados, como se deriva del hecho de considerarlos "parte del conflicto". Tal calificativo sugiere además que nacionales o extranjeros podrían declararse neutrales ante las partes, poniendo en igualdad de condiciones a los miembros de la fuerza pública y a los ilegales. (Citado por Valcárcel, 2007, p.112)

La segunda posición ratifica la existencia de un conflicto armado interno en Colombia y, en su refrendación en el debate público y la legislación nacional, reaparece con la promulgación de la Ley 1448 de 2011 (Ley de víctimas y de restitución de tierras), en la cual: "se dictan medidas de atención, asistencia y reparación integral a las víctimas del conflicto armado interno y se dictan otras disposiciones." (Subrayado fuera del texto original). En el Artículo 3 esta Ley señala que: "se consideran víctimas, para los efectos de esta Ley, aquellas personas que individual o colectivamente hayan sufrido un daño por hechos ocurridos a partir del $1^{\circ}$ de enero de 1985 , como consecuencia de infracciones al Derecho Internacional Humanitario o de violaciones graves y manifiestas a las normas internacionales de Derechos Humanos, ocurridas con ocasión del conflicto armado interno." (Subrayado por fuera del texto original).

Frente a la expedición de la Ley de Víctimas, y en relación con el reconocimiento del conflicto armado interno en Colombia, el presidente Juan Manuel Santos ha manifestado: 
- Si no hay conflicto armado interno, entonces no podemos bombardear a los jefes de la guerrilla, a los campamentos guerrilleros. Bajo el ámbito de los Derechos Humanos esto está prohibido, bajo el ámbito del Derecho Internacional Humanitario está permitido... (W Radio, 14 de mayo de 2011)

- Juan Manuel Santos dijo en Tumaco (Nariño), durante el lanzamiento del Plan Troya, que en Colombia "hace rato hay conflicto armado”. (Revista Semana, 4 de mayo de 2011)

Para el caso colombiano, la noción de conflicto armado interno ha sido reconocida e implementada jurídicamente, por cuanto ha posibilitado, entre otras cuestiones y en el marco de los tratados de derecho internacional suscritos por los gobiernos, determinar, delimitar y atender el universo de víctimas que puede ser sujeto de reparación por parte del Estado. Pero sus mayores discusiones se han dado en el ámbito político, por cuanto su definición y legitimación estatal corresponden a la línea ideológica de los gobiernos. Sin embargo, la implementación de políticas públicas que atiendan los rigores e incidencias del conflicto armado interno, necesariamente tienen que reconocer lo establecido en la normatividad internacional, para este caso, en lo expresado en el Protocolo II adicional a los convenios de Ginebra, que mediante la Ley 171 de 1994 fue adherido a la legislación colombiana y, por tanto, constituye integralmente el marco normativo a partir del cual interpretar lo que significa una situación de conflicto armado interno. En este instrumento internacional se señala:

\section{Artículo 1. Ámbito de aplicación material}

1. El presente Protocolo, que desarrolla y completa el artículo 3 común a los Convenios de Ginebra del 12 de agosto de 1949, sin modificar sus actuales condiciones de aplicación, se aplicará a todos los conflictos armados que no estén cubiertos por el artículo 1 del Protocolo adicional a los Convenios de Ginebra del 12 de agosto de 1949 relativo a la protección de las víctimas de los conflictos armados internacionales (Protocolo I) y que se de$\underline{\text { sarrollen en el territorio de una Alta Parte contratante entre sus }}$ fuerzas armadas y fuerzas armadas disidentes o grupos armados 
organizados que, bajo la dirección de un mando responsable, ejerzan sobre una parte de dicho territorio un control tal que les permita realizar operaciones militares sostenidas y concertadas y aplicar el presente Protocolo. (Protocolo II adicional a los convenios de Ginebra. Subrayado fuera del documento original).

Según analistas de este protocolo, son cuatro los elementos básicos constitutivos de un conflicto armado interno: “A) El conflicto tiene lugar en el territorio de un Estado; B) Se oponen las fuerzas armadas de este Estado a fuerzas armadas o grupos armados que no reconocen su autoridad; C) Estas fuerzas o grupos armados deben estar bajo el mando de una autoridad responsable; D) Estas fuerzas deben ejercer un dominio sobre una parte del territorio de dicho Estado, que les permita realizar operaciones militares sostenidas y concertadas, y aplicar las disposiciones del derecho humanitario del Protocolo II" (Swinarski citado por Valcárcel, 2007, p.114).

Ahora, para el caso de las experiencias alter comunicativas que realizan sus labores en zonas de conflicto, la noción de conflicto armado se amplía, por cuanto sus implicaciones afectan la vida cotidiana, el diario vivir de las comunidades que habitan los territorios convertidos en "teatros de operación" de los actores armados.

Así, desde la incidencia que el conflicto armado ha tenido en las dinámicas sociales, políticas, comunicativas, culturales y comunitarias de los territorios de influencia de las experiencias de alter medios vinculadas con el estudio, podemos señalar los siguientes elementos de análisis que aportan en la reflexión situada de las significaciones que los sujetos hacen de su realidad, y en el establecimiento de un sistema de representaciones que media en los escenarios de producción, distribución y socialización de la información. Miremos ahora los elementos de análisis identificados en las experiencias participantes, y sus aportes al debate nacional en lo relacionado con el cubrimiento del conflicto armado, su interpretación y representación social y mediática, desde una perspectiva local:

Elemento de análisis 1: El conflicto armado incide (ejerce presión) en las dinámicas comunitarias y comunicativas de los territorios. $\mathrm{Al}$ tiempo que los actores armados se disputan el territorio, también 
rivalizan por el posicionamiento simbólico de las premisas políticoideológicas en las que pretenden sustentar sus acciones bélicas. Para lograr este posicionamiento, los actores armados ubican "recursos" que, como los alter medios, facilitan la distribución social de los contenidos político-ideológicos en los que se inscriben. Para lograr este posicionamiento, los armados intentan ejecutar una "cooptación de facto" de los medios existentes en sus zonas de influencia. Dice el respecto Waira Jacanamijoy, de Ingakuna estéreo:

Había mucha presión por el lado del conflicto, por la guerrilla, que nos exigía meter muchos programas revolucionarios; iqué cosa, casi nos cuesta la vida!, porque hubo amenazas y todo eso. [...] Presión por el lado del Estado mismo, porque, en varias ocasiones el Ejército quiso tomarse los micrófonos para hablar de... del Ejército. [...] La cosa es que nos tocó decirles que no permitimos [intervención] ni de los unos, ni de los otros. Pero fue una presión muy grande, muy grande, la de estos grupos armados porque les diéramos voz. (Conversación personal con Waira Jacanamijoy de Ingakuna estéreo)

La distancia con los actores armados les han granjeado a los gestores de la alter comunicación, además de señalamientos y amenazas, un reconocimiento comunitario importante:

Por ejemplo, aquí en los espacios de Ocaina ha venido la solicitud de programas del Ejército, de la Policía, pero nosotros hemos optado porque estos espacios no pueden ser, porque peligramos los que estamos dentro del proceso de la radio, y eso nos ha permitido tener credibilidad y respaldo sobre todo de la gente. (Comunicación personal con Líverman Rengifo de Ocaina estéreo)

Por otro lado se reconoce a los gestores de la alter comunicación no solo como "hacedores de alter medios" sino, fundamentalmente, como líderes, como referentes comunitarios que velan por los intereses comunes, lo que les implica una mayor responsabilidad en lo que refiere a la salvaguarda de los procesos, las acciones y los recursos que sirven a la 
comunidad para defender sus posiciones de cara a superar o contrarrestar las dinámicas del conflicto armado. Al respecto señala Líverman:

Nosotros no solamente hacemos radio, sino también somos líderes comunitarios que tenemos proyectos con las comunidades y nos conocemos todas las veredas y a los presidentes de junta, los líderes comunitarios nos conocen a nosotros, eso nos ha facilitado también para estar en la región y para hacer un trabajo muy responsable desde la radio. (Conversación personal con Líverman Rengifo de Ocaina estéreo)

Al tiempo, los gestores de la alter comunicación señalan a la fuerza pública como un actor del conflicto que ejerce una presión significativa en las dinámicas comunitarias y comunicativas de los territorios. Ya lo han dicho Waira ("el Ejército quiso tomarse los micrófonos para hablar de... del Ejército") y Líverman ("ha venido la solicitud de programas del Ejército, de la Policía”). Por su parte Carlos Martínez Cuellar, de Piamonte estéreo, ratifica esta relación y asume, como en el caso de las otras experiencias, una posición en defensa de la autonomía comunitaria y de la libertad de prensa, y advierte entre líneas, que este tipo de decisiones podría generar, en algunos casos, “consecuencias":

No compartimos nosotros la violencia, no compartimos el ejercicio del conflicto armado; el actor que haya cometido el error, no lo compartimos y así lo hacemos saber a nuestro público, y gracias a Dios mayores consecuencias no hemos tenido, ni de parte de la fuerza pública ni con los actores del problema social. [...] Nosotros hemos sido un poco, digamos, prudentes y rectos en las cosas que decimos, y pues si cometieron ellos los errores, pues, igual no compartimos esos errores, porque todo debe estar dentro del concepto del amparo de la ciudadanía, de la protección del civil, porque para eso es que se han constituido las Fuerzas Militares... (Conversación personal con Carlos Martínez Cuellar de Piamonte estéreo) 
Ahora, tal es la presión que ejerce el conflicto armado en las regiones, y tal es su impacto en las dinámicas comunitarias y comunicativas de los territorios, que los temas relacionados con la guerra y la paz están silenciosamente vedados de la discusión pública.

De pronto esos temas no se los trata, pero la comunidad viene con las inquietudes... Nosotros no tratamos directamente con el conflicto armado, por cuestión de que dichos personajes que lo hacen, como son las Fuerzas Militares o los grupos al margen de la ley, hacen presencia en el territorio y eso representa un peligro para nosotros. Pero de todas formas la comunidad viene, cuando pasan casos, a pedir el apoyo de la radio comunitaria y nosotros tratamos de apoyar, tratamos de difundir la información para que todos estos conflictos tengan una solución. Y para eso nosotros nos encargamos de llevar los casos a las entidades que tienen la competencia de solucionar estos problemas. (Conversación personal con Jhon Jairo Vásquez de Piamonte estéreo)

Elemento de análisis 2: El conflicto armado fragmenta el tejido social, perturba las relaciones comunitarias y promueve el individualismo como estrategia de protección. En la memoria social de los gestores alter comunicativos se encuentran inscritos los procesos de ruptura del tejido social comunitario producto del conflicto armado: "En esta zona la gente por salvarse también hundía a los otros, ¿cierto?, como que nombraba al que fuera...", nos dijo en una conversación Waira Jacanamijoy, directora de la emisora indígena Ingakuna estéreo.

El conflicto armado genera, como parte de sus elementos constitutivos, un distanciamiento entre aquellos que otrora fueran vecinos, familiares, amigos, compadres, comadres. La ruptura del tejido social promueve nuevas relaciones entre los sujetos comunitarios, relaciones en las que los valores propios de la comunidad como la solidaridad, el compadrazgo, la minga, etc., se reconfiguran y dan paso a la sospecha, al recelo, al disimulo. La desconfianza se impone como criterio de acción y relacionamiento, no necesariamente porque la comunidad así lo decida, sino porque las dinámicas mismas del conflicto armado así lo imponen: 
Los alrededores del pequeño aeropuerto "Tres de mayo" de esta localidad [Puerto Asís, Putumayo] permanecen asediados por familias a la zaga de salir de la región [en el año 2000]. Unas miran con recelo a las otras y entre murmullos se acusan unas a otras de ser amigas de las guerrillas o de los paramilitares. Un soldado que ayudaba a prestar vigilancia en el lugar explicó que algunas lo hacían para que el Ejército sacara a otras de la fila que esperaba los aviones y así poder avanzar más rápido hacia la posibilidad de volar al destino que tuviera el carguero militar de turno. (Guillén, 2008, p.272)

Elemento de análisis 3: Existencia de un conflicto social estructural, en el que el conflicto armado es una de sus expresiones. Para los gestores de la alter comunicación el conflicto armado es una expresión del conflicto social, político y económico que se vive en las regiones del sur del país. En este sentido, el conflicto armado se entiende como subsidiario de otros conflictos relacionados con la propiedad de la tierra, con la producción agrícola y con la implementación de proyectos mineros, energéticos, petroleros y de infraestructura vial.

En otros momentos, como la década de los 90, el conflicto armado tenía profundos referentes en el problema cocalero que vivía el sur del país, los procesos de recuperación de tierras por parte de las comunidades indígenas, la colonización del piedemonte y las selvas amazónicas motivados por La Violencia y el olvido estatal de comunidades históricamente empobrecidas y obligadas a la diáspora permanente.

En los años ochenta uno de los factores que incidieron en el escalonamiento del conflicto político y armado en la zona fue la ruptura de las negociaciones de paz entre la guerrilla de las Farc-ep y el gobierno precedido por Belisario Betancourt Cuartas, así como el genocidio perpetrado con intensidad en las regiones sobre el partido político Unión Patriótica, que había sido dispuesto por la guerrilla como plataforma que posibilitaría la participación política de la insurgencia de cara a una posible desmovilización.

Frente a este panorama complejo, los procesos alter comunicativos regionales han entendido que buena parte de las fuentes que han 
motivado la existencia del conflicto armado perviven y, antes que reducirse, se multiplican en los últimos años con la implementación de políticas relacionadas con las llamadas "locomotoras del desarrollo nacional": la minería, el petróleo, las vías estratégicas de comunicación, la sustitución de cultivos ilícitos por monocultivos agroindustriales (palma aceitera, por ejemplo). Al respecto Waira y Líverman señalan lo siguiente:

- Aquí hay que hablar de conflictos, con s, en plural: conflictos... las épocas de conflictos en la región [en la Amazonía colombiana] han pasado por la coca, por la época del caucho, la época de la quina, bueno... muchos temas que han sido fuente de conflicto en la región... (Conversación personal con Waira Jacanamijoy de Ingakuna estéreo)

- Actualmente hay un problema que afecta mucho la región y es el tema de la minería, un tema muy complejo de tratar, porque ahí están inmersos no solamente grupos armados sino gente como narcotraficantes, todo lo que usted quiera... Entonces, este es un tema muy complicado, sin embargo nosotros vamos a las comunidades y miramos que en la reunión que estemos se pueda tratar el tema... si se puede lo hacemos, y esto nos ha dado algún resultado porque la gente de ahí tiene otra mirada frente a lo que le pueden brindar las empresas que llegan a hacer el tema de minería... (Conversación personal con Líverman Rengifo de Ocaina estéreo)

- Hay otro tema que actualmente se viene trabajando y es el tema de los hidrocarburos. Estos proyectos generan, por ejemplo, contaminación de aguas, por lo que hemos tenido varias reuniones, varios foros a nivel de las comunidades, porque en la radio no se puede tocar ya que en la zona maneja Ecopetrol y entonces el proyecto de tal comunidad no lo apoyan... entonces todo eso se vuelve complicado... (Conversación personal con Líverman Rengifo de Ocaina estéreo)

Elemento de análisis 4: La gobernabilidad como escenario de disputa. El mapa de problemáticas se complementa con los sistemas de 
corrupción, clientelismo y saqueo del erario (recursos públicos), prácticas que incentivan y promueven las dinámicas del conflicto armado, por cuanto las instituciones e infraestructuras públicas, así como los recursos, se convierten en objeto de disputa que acompañan los procesos de control territorial por parte de los actores armados, lo que genera un proceso de debilitamiento y deslegitimación del Estado en los territorios regionales y locales:

Tanto guerrillas como paramilitares han instrumentalizado las instituciones y mecanismos de la democracia. Las elecciones, por un lado, pero también los espacios de participación social, la protesta y los movimientos sociales como juntas comunales y sindicatos. Unos y otros han castigado con violencia los gestos de autonomía que han hecho las comunidades y los líderes sociales. (...) En estos años de guerra, el centro del país vio como se fortalecieron sus instituciones, mientras en la periferia subsistieron los problemas de gobernabilidad, la corrupción y la falta de legitimidad. El supuesto de que la descentralización ayudaría a cohesionar el país en medio de la diferencia y la diversidad, ha sido saboteado por los actores del conflicto. (CNMH, 2013b, pp.50-54)

La gobernabilidad se convierte, entonces, en un factor motivador del conflicto social y armado, lo que genera, al tiempo, una respuesta comunitaria y alter comunicativa que promulga la defensa de lo público como criterio fundamental. Esta defensa de lo público genera a los alter comunicadores y, en general, a los líderes críticos de los territorios, amenazas contra su vida, estigmatizaciones y criminalizaciones que hacen difícil el control ciudadano y la veeduría social sobre los recursos y las actuaciones de los funcionarios públicos:

En alguna ocasión tocamos unos temas, o se han venido tocando temas en la radio, sobre control ciudadano, de control sobre asuntos públicos que merecían una veeduría ciudadana, y tuvimos algunas amenazas verbales. Nosotros nos apoyamos mucho con el Colectivo de Abogados [José Alvear Restrepo] y ellos nos apoyan con algunas directrices [jurídicas y de veeduría ciudadana]. 
En la región no hay ese respaldo, pero a nivel nacional siempre estamos en contacto [con organizaciones defensoras de Derechos Humanos] y eso nos ha permitido crecer a nivel intelectual, para saber qué se puede tocar y que no se puede tocar. Sin embargo, hay que decir que las amenazas no vienen solamente por los grupos armados sino también por las instituciones del mismo Estado, llámese alcaldía, llámese hospital, alguna institución que de pronto no le gusta la temática que se está tocando... Pero digamos que ahí se ha logrado manejar las situaciones desde el diálogo... (Conversación personal con Líverman Rengifo de Ocaina estéreo)

Elemento de análisis 5: Existe una "pedagogía viva del conflicto armado" que dificulta el desarrollo de las "pedagogías vivas de la paz". Las acciones bélicas y simbólicas de los actores armados funcionan en el marco de una "pedagogía viva del conflicto armado", en tanto promueven modos de pensar, actuar y sentir, vinculados con el conflicto. En este sentido, la pedagogía viva de la guerra fomenta toda una serie de valores como la fragmentación social, la insolidaridad y el recelo por el otro, cuestiones que contribuyen en el moldeamiento socio cultural de las comunidades.

En tanto estrategia "pedagógica”, el conflicto armado no se inscribe en la lógica de un currículo formal ni necesita de infraestructura distinta a la que se promueve desde la misma guerra. Es una "pedagogía" presente en todos los lugares y en todas las actividades de las comunidades, que incide en los sistemas de relaciones y representaciones a partir de los cuales actúan socialmente los ciudadanos. Al tiempo, es una pedagogía que se ubica, literalmente, en escuela formal. El conflicto determina las acciones pedagógicas de las escuelas de las zonas con influencia armada, como en el caso de la Institución Educativa Indígena Inga Yachaicuri, ubicada en el Caquetá:

El conflicto pasa por la Escuela y por todo el proyecto en lo educativo. Se evidencia en que los niños no pueden salir a hacer sus registros [recorridos, "trabajo de campo"] en su propio territorio. Nos pasó un caso donde varios profesores salieron a hacer un recorrido, que es lo común que se hace en el colegio, y resulta que se 
encontraron con unos cilindros [bomba] dentro del territorio. (...) Entonces, el conflicto pasa por toda la escuela, por todo el proceso pedagógico. Cuando estuvimos en ceremonia [de Ayahuasca o Yagé, que hace parte de la estrategia pedagógica propia del pueblo Inga], el Ejército empezó a armar un discurso que no sabemos... puede ser verdad: en plena ceremonia, el Ejército como por cinco ocasiones empieza a disparar, a hacer ráfagas, con el argumento de que "cada que los indios van a tomar yagé, aparece un señor que vuela, un monstruo que vuela por los árboles", entonces dicen que a ellos les da como susto y lo que hacían era dispararle a ese hombre que veían para poder protegerse. Y eso era cada vez que había ceremonia... (Conversación personal con Waira Jacanamijoy de Ingakuna estéreo)

La guerra también determina una serie de "saberes" que posibilitan a las comunidades hacer frente a las dinámicas del conflicto. Las comunidades "saben por dónde caminar", establecen los sitios que han sido vedados por los actores armados, establecen unas formas de comportamiento social en consecuencia con las imposiciones del conflicto. Como ejemplo reseñamos el hecho de que en desarrollo del trabajo de campo de este proyecto, cada vez que solicitábamos acompañamiento para realizar un recorrido, los amigos de cada zona nos decían: "Ustedes para qué van a ir por allá... Para qué se van a meter por allá... Eso por allá es peligroso... Por allá les puede pasar algo..."

El conocimiento que las comunidades tienen de sus propias circunstancias en relación con el conflicto armado, los ha llevado a delimitar espontáneamente sus prácticas para que puedan sortear dificultades concretas. Estos conocimientos y prácticas de resistencia al conflicto, posibilita a los habitantes de estas regiones comprender lo que se puede y lo que no se puede hacer, lo que se debe y lo que no. Saben estos sujetos por dónde se puede o no caminar, con quién se puede o no hablar, han establecido las rutas, los gestos, los signos de la guerra, y actúan en consecuencia, no solo por la imposición, sino como forma de resistencia a la acción de los armados.

En este sentido, comunidades y sujetos adecúan su práctica social a las dinámicas impuestas por el conflicto y, de alguna manera, 
naturalizan estas prácticas, por cuanto son ellas las que les permiten sobrevivir a contextos en los que "o te acostumbras o te vas o te mueres":

La vida cultural de muchos pueblos, sus relaciones sociales, costumbres y creencias fueron alteradas completamente por la guerra. Los actores armados reprimieron o impusieron las fiestas, el trabajo comunitario, la solidaridad y el duelo. Se propagó la desconfianza, imperó el aislamiento, se imposibilitó la ocupación de los espacios de la vida pública y se distorsionó su naturaleza con marcas de terror, se perdieron prácticas culturales y se les impusieron a las comunidades nuevas concepciones del orden social. La nuestra no ha sido solo una guerra por el territorio, también ha sido una guerra por la imposición de nuevos órdenes sociales basados en valores autoritarios. (CNMH, 2013b, p.62)

De este modo la guerra impone la criminalización de las prácticas culturales de las comunidades y, sobre todo, restringe una serie de prácticas puntuales propias de, por ejemplo, culturas ancestrales, que constituyen los imaginarios sociales de comunidades enteras. A estas prácticas diversas se les imputan valores que no les son propios, con lo cual se estigmatizan y criminalizan, lo que interrumpe su proceso de reproducción al interior de las comunidades.

Frente a esto, las mismas comunidades responden re-significando sus prácticas socioculturales, donde las pedagogías de la paz y los procesos alter comunicativos cumplen un papel fundamental, en la medida que se convierten en estrategias y recursos simbólicos para el reposicionamiento de las memorias y las acciones colectivas: "nos tocó a nosotros llamar al Ejército y decirles que por favor tuvieran respeto... Ustedes están en territorio nuestro y tienen que respetar nuestras tradiciones. Entonces por eso digo que el conflicto no pasa por fuera, está adentro." (Conversación personal con Waira Jacanamijoy de Ingakuna estéreo)

Elemento de análisis 6: La intimidación de la población civil como estrategia de guerra para vencer al enemigo. Las acciones de guerra ejecutadas sobre la sociedad civil han tenido como blanco fundamental 
a los líderes de las comunidades. Atentando contra el líder, en conjunto se repliega hacia el anonimato y la deliberación pública se reduce a su mínima expresión:

Lastimosamente en el año 98 cuando estaba para iniciar el proceso de la radio [de la emisora Ocaina estéreo] asesinan al Padre Alcides Jiménez, que era el promotor de muchos procesos, no solamente en Puerto Caicedo, sino en el departamento del Putumayo. A Alcides lo recuerdan alrededor de los seis municipios del Bajo Putumayo, como el gestor de todos los procesos comunitarios a nivel del departamento, con él se tenían proyectos con embajadas internacionales, y algunos de estos procesos se perdieron con la muerte de él, porque no se tuvo la experticia en que esto iba a suceder y no se tuvo un relevo generacional de quién podría asumir la responsabilidad. Nosotros como Corporación Nuevo Milenio, pues fue también difícil porque hubo muchas amenazas a raíz de la muerte de él, paramos el trabajo alrededor de seis meses y luego tomamos la decisión de nuevamente retomar actividades. (Conversación personal con Líverman Rengifo de Ocaina estéreo)

La intimidación de la población civil funciona, entonces, como dispositivo de silenciamiento, con todo lo que ello implica en relación con la construcción de las esferas públicas locales y el agenciamiento social del debate de las cuestiones públicas.

El posicionamiento estratégico de los actores de la guerra es, en este sentido, territorial y simbólico. Con él se pierde la pluralidad política y comunicativa, y se vincula al conjunto de la comunidad con una estrategia de posicionamiento frente al enemigo que le es impuesta. La intimidación sirve, de este modo, como estrategia de cooptación social que coloca los proyectos comunitarios y personales a disposición de los actores armados, en tanto los instrumentaliza o los silencia:

Nosotros estamos en un cruce de balas, y lo que nosotros estudiamos es que tal vez sea estratégico entre los dos bandos que se posicionen así, ya que nosotros quedamos en el medio. Estamos expuestos a que nos caigan artefactos... El otro día, hace unos meses, yo no 
sé cómo no pasó algo grave porque había un enfrentamiento entre el Ejército y los otros [las Farc-ep] que tiraron una bomba y cayó entre la emisora y otra casa... menos mal que no estalló la bomba. ¿Se imagina nosotros con todos esos niños que tenemos ahí en el colegio? Uno ya no sabe qué hacer, si quedarse callado o denunciar. ¿Pero denunciar a quién? (Conversación personal con Waira Jacanamijoy de Ingakuna estéreo)

Elemento de análisis 7: No existe la "neutralidad y objetividad" en medio del conflicto armado. Los actores armados que agencian la guerra en las regiones pretenden obligar a la población civil a "tomar partido" por su causa. A pesar de la intimidación, muchas comunidades han optado por la paz representada en las causas comunitarias. Esta posición, para el caso de los alter comunicadores pone en discusión uno de los criterios fundamentales de la prensa liberal y del régimen hegemónico: el de la objetividad y neutralidad periodísticas.

Al contrario de aquel periodismo que dice no comprometerse con nada (pero que en lo profundo está comprometido con intereses políticos y económicos hegemónicos), los gestores de la alter comunicación en zonas de conflicto dicen comprometerse con las causas de sus comunidades, en un acto de solidaridad y resistencia que posibilita la recuperación de las confianzas y las vocaciones comunitarias para el encuentro y el debate público, el rescate del sentido político de la acción común, así como la reivindicación de la memoria y la imaginación como dispositivos para la reconstrucción de las dignidades arrebatadas:

Hay que tener en cuenta, y esto lo aprendíamos del Padre Alcides, es que de alguna manera lo neutral no existe, no, porque de todas maneras hay que estar de algún lado y siempre nosotros vamos a estar al lado de la comunidad, lo que nos ha facilitado el trabajo, porque nosotros nunca estamos, digamos, de parte de la fuerza pública o de otros actores armados, sino de parte de la comunidad. (Conversación personal con Líverman Rengifo de Ocaina estéreo) 
Elemento de análisis 8: El conflicto armado son los actores armados en el territorio. La noción de conflicto armado se hace un tanto extraña para los pobladores de los territorios de influencia de las experiencias alter comunicativas Ocaina estéreo, Piamonte estéreo e Ingakuna estéreo. A eso, que desde las centralidades se ha denominado como "conflicto armado", los habitantes de estos territorios le llaman guerra, aunque de la guerra no se habla mucho, debido a su presencia persistente en todos los aspectos de la vida social y comunitaria.

Para referirse al "conflicto armado", Jhonny nos dijo que eso era la gente que estaba en el monte y que se enfrentaba con el Ejército. En una conversación informal, Carlos nos dijo que no entendía muy bien eso que nosotros llamábamos “conflicto”. En estas regiones del sur del Cauca, del Putumayo y del Caquetá se representa y nomina el conflicto desde "los enfrentamientos", "los asesinatos", "los que están en el monte", pero el "conflicto armado" como lo vemos y conocemos en la centralidad de las ciudades es, en realidad, algo distante en tanto denominación.

Los habitantes de estas zonas saben que hay conflicto armado porque "vemos caminar a los armados por nuestro territorio, están aquí", señaló Alexander. De la guerra, del conflicto armado, no se habla en abstracto: por estas tierras a la gente le toca recoger los cilindros bomba de sus propios patios, le toca ser prudente cuando se interna en los potreros para la siembra y el cultivo. La gente sabe del conflicto no porque lo ve en televisión, sino porque sabe que su palabra está restringida a lo que socialmente se ha establecido hablar. Se habla poco y en tono muy bajito de la guerra, porque para qué hablar de lo que se ve todos los días:

Una vez que entraron por aquí los paramilitares marcaron los cuadernos de los niños con cosas como: "somos de las AUC, bloque yo no sé qué”, y así, con informaciones de ese tipo. Y lo mismo la guerrilla, que se la pasan incentivando a los niños para que se vayan al combate, conquistándolos ideológicamente. Entonces por aquí es muy fuerte, en cualquier momento se ve muy fuerte... (Conversación personal con Waira Jacanamijoy de Ingakuna estéreo) 
Las marcas que dejan los actores del conflicto sobre los sujetos y el territorio son múltiples. Un ejemplo revelador son aquellas que dejaron los soldados del Ejército en la infraestructura de la torre de transmisión de la emisora indígena Ingakuna estéreo. Con elementos filosos los soldados grababan sobre el pañete de cemento y sobre las puertas de metal consignas como: "Escorpión 3. Moral a 6 meses de la mocha", "Ayuden a los que queden. Ay dolor”, "Entonces qué camaradas, bien o qué HP. Att. Ejército”.

Figura 20. Marcas grabadas por soldados del Ejército Nacional en instalaciones de la torre de transmisión de la emisora indígena Ingakuna estéreo

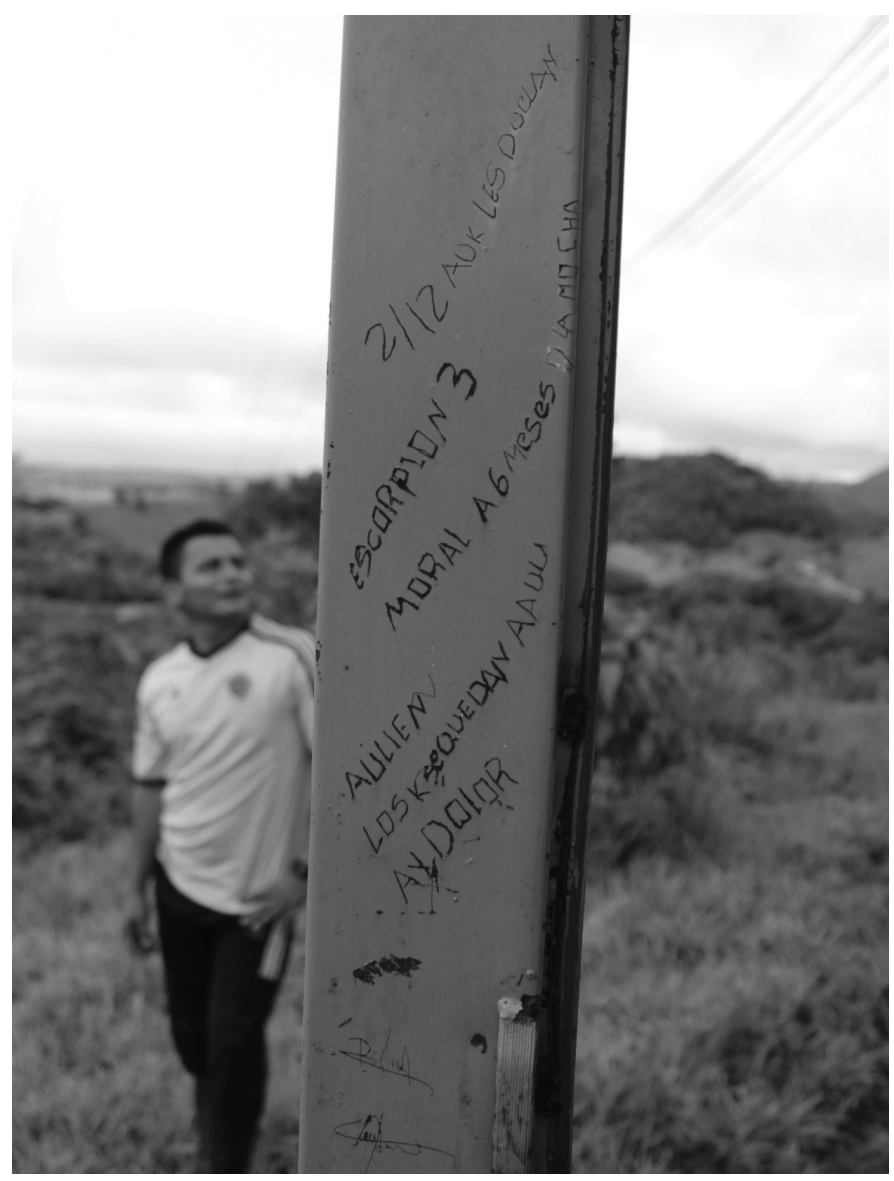

Fuente: Archivo grupo de investigación. 


\section{Representaciones alter comunicativas de la paz y el posconflicto}

En la campaña electoral para la presidencia de la República de 2002, el candidato Álvaro Uribe Vélez, del movimiento Primero Colombia, presentó su Manifiesto democrático. Este documento se convirtió en la hoja de ruta de su primer gobierno, por cuanto fue el resultado, según ha señalado el mismo Uribe, de un proceso de consulta ciudadana amplia y participativa que se adelantó en múltiples talleres. El punto 41 de este manifiesto atiende al apartado "En busca de la paz”, y señala que:

Soy amigo del diálogo con los violentos, pero no para que crezcan sino para hacer la paz. Pediré mediación internacional para buscar el diálogo con los grupos violentos, siempre que empiece con abandono del terrorismo y cese de hostilidades. Para el desarme y la desmovilización puede haber todo el plazo que se requiera. Urgencia para el cese de hostilidades, paciencia para los acuerdos finales. Toda la generosidad en la reinserción. Garantías efectivas para el ejercicio político de quienes provengan de los grupos armados; que hagan política sin armas y sin que los asesinen. (Uribe, 2002)

La búsqueda de la paz tiene que ver, aquí, con la restricción del ejercicio de la violencia (del terrorismo, dice Uribe) por parte de "los violentos". Los violentos son aquellos que utilizan el ejercicio de la violencia armada por fuera de las fuerzas legítimas del Estado, que junto a su fuerza pública y desde esta perspectiva, no ejercen violencia sino que se instituyen como instancia legítima de la democracia que, incluso utilizando el ejercicio de la violencia armada, debe velar por la paz. El mecanismo del diálogo como instrumento para llegar a la paz que se busca, está condicionado por "el abandono del terrorismo y cese de hostilidades".

El Acto Legislativo 01 de 2012, conocido como el Marco jurídico para la paz, establece instrumentos jurídicos de justicia transicional a partir del artículo 22 de la Constitución Política y dicta otras disposiciones para, en perspectiva de la justicia, atender las necesidades que implica un proceso de negociación de la paz en medio del conflicto armado. 
Por otro lado, en la instalación de la mesa de negociación de la paz entre el gobierno nacional precedido por Juan Manuel Santos y la guerrilla de las Farc-ep, dada en Oslo, Noruega, el 18 de octubre de 2012, el vocero del gobierno, Humberto de la Calle Lombana, señalaba que:

Hay un punto en el que coincidimos con las Farc, la finalización del conflicto no es en sí misma la consecución inmediata de la paz. La fase tres es el escenario para las transformaciones necesarias que serán el verdadero motor de la paz, el gobierno ha puesto en marcha una agenda audaz para introducir cambios sociales profundos en nuestra sociedad, tiene una agenda progresista, el gobierno ha reconocido la inequidad y desigualdad existentes en Colombia pero no se limita al diagnóstico, hoy hay en marcha una transformación de la realidad social en Colombia y las Farc tienen la posibilidad de unirse a ella sin dejar su condición de contraparte al sistema para catalizar el proceso. (De La Calle, 18 de octubre de 2012)

Al tiempo, el representante de las Farc-ep en la instalación de la mesa de negociación, Iván Márquez, daba inicio a su discurso citando palabras de Manuel Marulanda Vélez, fundador y comandante de las Fuerzas Armadas Revolucionarias de Colombia hasta el año de su muerte (2008): "Nuestro sueño: la paz con justicia social y soberanía. La paz que hemos querido nosotros, por la cual hemos luchado por mucho tiempo, ha sido siempre buscando que en este país, Colombia, se acaben las desigualdades que son tan poderosas." (Márquez, 18 de octubre de 2012)

Para el caso colombiano, la paz además de ser un propósito permanente, es una noción anclada al discurso público nacional. Las menciones a la paz son recurrentes en los círculos políticos, en los medios de comunicación, en los eventos académicos y hoy, en general, en la conversación ciudadana que refiere a temas públicos. Independiente de si se está a favor o en contra del "proceso de paz", la paz en tanto noción hace presencia en el debate nacional. 
En el plano político, todos los actores nacionales dicen estar a favor de la paz, aunque existen diferencias radicales sobre los mecanismos para llegar a ella. Para el caso de la denominada "(ultra) derecha" colombiana (representada en la figura de Álvaro Uribe Vélez y su partido Centro Democrático), la paz se consigue por la vía de la derrota militar del adversario (que se consolida en los presupuestos de la que se denominó como "Política de seguridad democrática"). Para el caso de los sectores políticos de centro e izquierda (Partido de la U, Cambio Radical, Polo Democrático Alternativo, Partido Verde, Progresistas, etc.), la respuesta al conflicto y la búsqueda de la paz se debe dar por la vía de un acuerdo político entre las partes en conflicto y "con justicia social”. Para el caso de la "(ultra) izquierda”, la búsqueda de la "justicia social” que lleva a la paz pasa por la derrota militar del adversario, en este caso, las oligarquías representantes del status quo.

El espectro político, entonces, está a favor de la paz, esa instancia socio política que se busca como alternativa al conflicto. Pero, como señala Johan Galtung (2003), la existencia de un conflicto no necesariamente indica la ausencia de la paz, así como la existencia de la paz no indica, necesariamente, la ausencia de conflictos. Lo que existe es una relación dialéctica entre paz-conflicto que desaparece cuando en el marco de un conflicto se utiliza la violencia como estrategia de resolución, con lo cual nos aproximamos a una primera definición de la paz, la cual podría entenderse como: "ausencia de violencia directa, estructural y cultural $(\mathrm{Paz}=$ paz directa + paz estructural + paz cultural)." (Galtung citado por Hueso, 2000, p.131).

Esta definición tiene como eje fundamental la violencia, por lo cual el mismo Galtung, el "teórico de la paz” más reconocido actualmente en el mundo occidental, ha subrayado sus limitaciones, proponiendo una definición menos estática. En la interpretación que Hueso hace de las teorías de la paz de Galtung, se señala que:

Paz es la capacidad de manejar los conflictos con empatía, no violencia y creatividad. La empatía se entiende como el acto de compartir cognitiva y emocionalmente, sentir y entender las pasiones del otro sin estar necesariamente de acuerdo con todo ello. Empatía no es solidaridad. Galtung define creatividad como la capacidad 
para ir más allá de las estructuras mentales de las partes en conflicto, abriendo nuevos caminos de concebir la relación social en la formación del conflicto. El verdadero test de la paz, según Galtung, es la habilidad para tratar un conflicto, manejándolo creativamente, transcendiendo las incompatibilidades y actuando en el mismo sin hacer uso del recurso de la violencia. Si la paz es un sistema dentro de un contexto, se necesitan ciertas condiciones para que ese sistema no se desequilibre. Un sistema donde predomine la paz, requiere una cultura y estructura de paz y así, y solo así, se puede desterrar la violencia. (Hueso, 2000, pp.131-132)

Ahora miremos como desde las experiencias alter comunicativas que trabajan en zonas de conflicto se amplían los referentes de análisis de estas definiciones sobre la paz que, siendo pertinentes, merecen ser revisadas a la luz de las condiciones particulares de aquellos actores sociales que "viven y sufren el conflicto". A partir de los diálogos testimoniales con los gestores de la alter comunicación vinculados con el estudio, se pueden identificar cuatro elementos de análisis que revelan modos particulares de entender "la paz" en zonas de conflicto armado. Ellos son:

Elemento de análisis 1: La paz es el proceso de La Habana, es una paz institucional. A la paz se le ve y entiende, de manera instrumental, como un proceso de negociación entre un gobierno nacional lejano, distante, abstracto para la realidad de las comunidades que han vivido inscritas históricamente en las dinámicas del conflicto armado, y un actor armado que, como las Farc-ep, han representado los sistemas de orden y autoridad en los territorios de su influencia.

Es común escuchar en estas zonas, que a pesar de las negociaciones en La Habana, Cuba, la situación en los territorios no cambia radicalmente. Por ejemplo, y tal como se señaló en el capítulo tres (caracterización de las experiencias), hay situaciones cotidianas de violencia que involucran a los actores armados y que dejan entrever cómo las condiciones propias del conflicto siguen vigentes en algunos territorios: 
Poco antes de las 8 de la noche, a unos 50 metros de donde estábamos ubicados, en una taberna detonaron unos disparos: primero una seguidilla como de 5 o 6 , y segundos después otra, de 3 o 4 tiros. Dicen que [las víctimas] son mujeres de guerrilleros, y que por eso las están matando...

Así, las condiciones del conflicto armado y la presencia de los actores de la guerra perviven, más allá de las negociaciones entre las partes, cuestión que de todas maneras no desconoce para los alter comunicadores algunas sutiles transformaciones en las dinámicas del conflicto, sobre todo en momentos de tregua armada.

Elemento de análisis 2: La paz como posibilidad de crecimiento económico y social. Asumiendo que a la paz se le entiende por parte de los alter comunicadores como un proceso de negociación de las partes en conflicto, se espera que el resultado de los acuerdos se materialice en aspectos que beneficien de manera real a las comunidades. Una de esas materialidades tiene que ver con un reclamo histórico de las gentes de estos territorios del sur del país: la posibilidad de crecimiento económico para las comunidades y los individuos.

En lo que tiene que ver con las comunidades, se espera que el escenario de la paz posibilite una mayor inversión del Estado en infraestructura social: escuelas, hospitales, vías, servicios públicos, subsidios para el desarrollo agropecuario e industrial, etc. En lo que se refiere al desarrollo individual, la gente espera poder acceder a procesos de capacitación técnica y profesional, esperan progresar y "sacar los hijos adelante, para que no les toque tan duro", esperan mejorar su nivel de vida por la vía de un capital que les permita acceder a bienes y servicios de consumo básico y, sobre todo, a la propiedad de la tierra y recursos técnicos y financieros para trabajarla.

La paz es, entonces, un camino que podría conducir hacia el progreso, una ruta que posibilitaría el ingreso de estos pobladores al ejercicio pleno de sus garantías ciudadanas, representadas en acceso a recursos que les permita integrarse en los sistemas de producción y consumo de bienes y servicios.

En segundo lugar, se asume que la paz podría funcionar como estrategia para la consolidación de proyectos políticos incluyentes, 
plurales, participativos, aunque frente a este aspecto se tienen profundas reservas, resultado de los antecedentes que en el plano de la organización y la acción política les ha tocado vivir, pues hay cosas que no se olvidan:

Cuando estaba empezando a trabajar en la radio yo aparecí amenazada, en el 2003, como auxiliar de la guerrilla. Me ha demandado alguien, un NN, en Bogotá, en la época de Uribe. Y bueno, yo creo que se siguen repitiendo muchas cosas de estas, muchos señalamientos a nivel del departamento... (Conversación personal con Waira Jacanamijoy de Ingakuna estéreo)

Elemento de análisis 3: La paz como incertidumbre. “QQué va a pasar con los desmovilizados?, ¿qué les van a poner a hacer?, ¿dónde los van a ubicar?" Estos son interrogantes que surgen en los territorios de influencia de los grupos armados. Hay una incertidumbre permanente por parte de la población civil frente a la relación que van a establecer, ahora en la "legalidad", con los victimarios. Porque una cosa es la relación social de subordinación que genera el ejercicio de la violencia, y otra entender al victimario en la misma condición social de la víctima.

En estos territorios la población civil ha convivido con los actores armados: en muchos casos saben quiénes son, quiénes han sido, de dónde vienen, a qué familia pertenecen. Y saben hasta dónde han llegado en el ejercicio de la violencia sobre sujetos y comunidades. Por ello los procesos de negociación generan algún entusiasmo frente al desescalonamiento del conflicto y el impacto que este ha causado en las comunidades y la población. Pero al mismo tiempo, y con mayor contundencia, genera desconfianzas e incertidumbres ante ese nuevo estado de cosas que se ve venir con el proceso de reintegración de los combatientes a la vida civil:

Las diferentes instituciones del gobierno nacional deberían dar a conocer, por los diferentes medios, cuál es el plan a seguir para que realmente esta gente que está involucrada en el conflicto retorne a sus lugares y no sea problema ni para la vereda, ni para el municipio, ni para la sociedad... La gente necesita saber esa 
gente dónde va a vivir, porque en nuestro municipio no se tiene claridad sobre esto: si habláramos de la Alcaldía, no tiene claridad sobre cómo debe trabajar para recibir a una gente que a lo mejor tenemos en el monte y que a lo mejor no sabe qué viene a hacer a la cabecera municipal o a su vereda.

Nosotros consideramos que el gobierno debe dar a conocer, por los medios de comunicación, los modelos con los cuales se va a atender esta reintegración de esta gente, para que nosotros los aceptemos... Porque nosotros no queremos delincuencia, tenemos miedo de que esa gente venga a formar otros grupos que terminen secuestrándonos a nuestros hermanos, a nuestras mismas familias, cuando al contrario lo que buscamos es que el gobierno les abra unos programas, que sean atendidos hasta psicológicamente, $\mathrm{y}$ que también sean apuntalados con muy buenos recursos para que también generen empresas, generen empleos y para que de alguna forma se vinculen a la sociedad civil. (Conversación personal con Carlos Martínez Cuellar de Piamonte estéreo)

Por otro lado, están los antecedentes de otros procesos de negociación del conflicto armado que han sido fallidos. La ruptura de estos procesos ha agravado la situación de orden público en las zonas donde la guerra se ha posicionado, y ha generado el recrudecimiento de las acciones bélicas, con todo el impacto que esto puede traer para la población civil.

También hay que tener en cuenta que los acuerdos de paz recientes, y sus procesos de desmovilización y reintegración de combatientes (sobre todo el implementado por el primer gobierno de Álvaro Uribe con los grupos paramilitares en 2005), degeneraron en una "balcanización" del conflicto. Hubo un proceso de "reciclaje paramilitar" que resultó en la conformación de bandas criminales (bacrim) que se dispersaron por todo el país. Estas bandas entraron en pugnas por el negocio del narcotráfico y otras fuentes de financiación de la guerra, generando a su vez procesos de delincuencia común que luego pretenden ser presentados como delitos de carácter político.

Todas estas circunstancias, sumadas a la desconfianza hacia el Estado, generan en las comunidades y los líderes locales mayores 
suspicacias y desconfianzas que certezas y tranquilidades. A la paz se le ve, entonces, como fuente de preocupaciones, más que como comienzo efectivo de nuevas oportunidades. En aquellos territorios donde la guerra ha sido la certidumbre, la paz representa una constante incertidumbre:

Nosotros hemos planteado a nivel de municipio y con algunas instituciones del departamento, la posibilidad de conocer más de cerca cuál sería la metodología y cuáles serían los espacios que deben de crear para apoyar el diálogo. Por ejemplo nosotros como emisora comunitaria, cuál podría ser nuestro papel fundamental para poder contribuir en este posible diálogo, que buscamos que realmente sea efectivo, que permita que nuestra gente misma que está en el monte pueda retornar a sus tierras, a sus veredas y a su municipio, pero pues donde también tenga la posibilidad de ser reconocido y aceptado ante la sociedad.

Nosotros hemos dejado claro en algunas participaciones a nivel de departamento que como emisora estamos prestos a buscar y a impulsar la metodología que se decida, a hacer programas que de alguna forma den a conocer a quien esté en la ruta de poder volver a la sociedad, pero parece que ni las autoridades están preparadas para asumir eso. (Conversación personal con Carlos Martínez Cuellar, Piamonte estéreo)

Elemento de análisis 4: “¿Cómo va la paz?, ¿cómo se nombra la paz? De eso no sabemos casi nada." Para el caso de los alter comunicadores, se evidencian dificultades para "nombrar la paz institucional", aquella que se discute en el proceso de negociación de La Habana. Esa paz institucional, que es lejana para los pobladores de estos municipios, es difícil de contar en estas regiones:

El proceso de paz se escucha por los adelantos y los atrasos, de él sabemos por los que escuchamos en televisión o por la radio. Pero realmente en el departamento [del Caquetá] y sobre todo en el municipio [de San José del Fragua], no sabemos nada, absolutamente nada... De las situaciones del proceso, de qué están negociando, no 
sabemos. De quiénes están ahí negociando y tratando las diferentes problemáticas que hay, por ejemplo, a nivel de poblaciones indígenas, tampoco sabemos. Realmente estamos descontextualizados de lo que están negociando al nivel de La Habana... (Conversación personal con Waira Jacanamijoy, Ingakuna estéreo)

Ahora, de la paz que se construye en el día a día, esa paz que, como señala Galtung (2003), busca "sentir y entender las pasiones del otro sin estar necesariamente de acuerdo con él”, de esa sí saben los gestores de la alter comunicación y las comunidades con las que se vinculan. Esa es una paz representada en el trabajo comunitario, en los intentos por defender los recursos públicos, en los esfuerzos por preservar la cultura y las tradiciones, en el ejercicio de vincular cada día a más gente en "este cuento tan bonito de la comunicación”, como diría Carlos Martínez Cuellar.

Con todo y que la paz institucional sea casi que un referente abstracto para la gente de estos territorios, la otra paz, la que se intenta gestionar desde los procesos comunitarios y comunicativos, está presente "en lo que se sabe y en lo que se hace", como diría Waira:

Lo que nosotros hacemos es abordar temas de los que conocemos. Entendemos que la radio es un poder para decir algo sobre todos los temas, pero si no conocemos el tema a profundidad, tomamos la decisión de no hablar de eso... Entonces, nosotros lo que hemos venido proponiendo desde la emisora es, por ejemplo, hablar sobre el tema de gobernanza, pero desde nosotros los indígenas, no desde lo que se nos quiere imponer desde afuera..." (Conversación personal con Waira Jacanamijoy de Ingakuna estéreo)

Por su parte Carlos Martínez Cuellar ha dicho:

Nosotros estamos muy de acuerdo con los diálogos [de paz de La Habana], pero nosotros partimos del principio de que las cosas tienen que llegar hasta el momento donde se pueda entender el por qué del conflicto, y en dónde estaría el principio de una solución, porque si no se conoce lo que se va a solucionar, el proceso 
fracasa. (Conversación personal con Carlos Martínez Cuellar de Piamonte estéreo).

Y mientras se conoce aquello que se tiene que solucionar, los gestores de la alter comunicación en zonas de conflicto solucionan los problemas que conocen.

Por ejemplo Líverman Rengifo y el equipo de Ocaina estéreo, quienes han tenido que vivir en carne propia los rigores del conflicto armado, no se han quedado sentados esperando los resultados de una negociación todavía etérea para ellos. Frente a estos rigores de la guerra han tomado decisiones que les permiten, primero, salvaguardar la vida y, segundo, dar continuidad a los procesos que con tanto esfuerzo han venido gestionando. $\mathrm{Y}$ este accionar ha sido una constante en su historia organizativa, más allá de las decisiones "de guerra o de paz” que tomen los actores del conflicto y la institucionalidad estatal:

Hacia el año del 2001 viene toda la incursión paramilitar acá en el municipio [de Puerto Caicedo], se tomaron las instalaciones de la torre [de transmisión] de la emisora comunitaria; para nosotros fue difícil porque nos mirábamos como objetivo militar. (...) Sin embargo logramos permanecer en la región hasta el año 2005 que fue cuando nos amenazan a dos radialistas de acá; ellos tuvieron que salir, porque no tenemos las posibilidades de decir que podemos enviarlos a otro lugar, entonces tuvieron que salir hacia la capital del departamento del Putumayo, que es Mocoa. Actualmente ellos se encuentran en Mocoa haciendo trabajo periodístico, con organizaciones y con emisoras no comunitarias, comerciales, pero que vienen haciendo también un trabajo muy importante. (Conversación personal con Líverman Rengifo de Ocaina estéreo)

$$
* * * * *
$$

En lo que tiene que ver con el posconflicto, categoría relativamente nueva en las discusiones que sobre la paz y la guerra han formulado los gestores de las experiencias participantes, ubicamos tres elementos de análisis 
claves para interpretar la manera como se asume el "fin del conflicto armado" por parte de los alter comunicadores del sur del país. Aquí se habla de posconflicto, sin entrar en el debate académico e institucional que propone problematizar el escenario y hablar de "pos acuerdo". Estos, que son debates importantes en las centralidades políticas, académicas e institucionales colombianas e internacionales, no tienen mayor desarrollo en las zonas de influencia de las experiencias alter comunicativas vinculadas al estudio.

Miremos, entonces, cómo se reflexiona el "posconflicto” desde estas experiencias, a partir de las reflexiones propuestas por los alter comunicadores que trabajan en zonas de conflicto armado y social:

Elemento de análisis 5: La discusión sobre el posconflicto ha sido agenciada por la institucionalidad. El posconflicto en tanto noción tiene un importante recorrido analítico e interpretativo público en el país. Algunos sectores políticos y académicos han venido trabajando en su discusión a la luz del contexto y las particularidades nacionales, y en los últimos años, a la par con el desarrollo del proceso de negociación en La Habana, se han gestionado múltiples espacios de deliberación pública para informar a la ciudadanía sobre las concepciones, percepciones e implicaciones del posconflicto, en el marco de los posibles acuerdos.

En este contexto de deliberación podemos considerar, de manera muy general, que el posconflicto es "aquel periodo de tiempo que se inicia con el cese de hostilidades entre las partes previamente enfrentadas” (Rettberg, 2002, p.17). A esta sucinta definición Ayala y Hurtado agregarían que,

el posconflicto no puede entenderse como un fin último, sino como un proceso en el que hay varias tareas por hacer, entre ellas, el fortalecimiento, e incluso la refundación del Estado y, por ese camino, el logro de una legitimidad amplia y plural que reemplace el imaginario negativo que de este, tienen amplios sectores de la Nación. (Ayala y Hurtado, 2007, p.37)

Frente a esto, Líverman ha señalado que el hecho de que el proceso de paz no se conozca lo suficiente, lleva a que la noción misma de posconflicto pierda sentido en los territorios afectados por el conflicto armado: 
Lo que uno encuentra es que la gente no sabe, no conoce o no le importa lo que se está negociando, porque dice el campesino que vive ahí con el comandante, con la guerrilla, que aquí las cosas son a otro precio y que por eso no interesa mucho lo que se negocie y se defina por allá [en La Habana]. (Conversación personal con Líverman Rengifo de Ocaina Estéreo)

Ahora, como los medios de comunicación cumplen funciones tanto informativas como formativas, y teniendo en cuenta que los alter medios asumen críticamente estas funciones, las experiencias han buscado, con muchas limitaciones, entrar en el debate que se plantea en torno al posconflicto, el cual surge más como una imposición de las circunstancias propias de la negociación, que como una realidad de los territorios y las comunidades.

Con todo, algunos alter medios como Ocaina estéreo han realizado incluso gestiones para establecer más que una línea editorial, una decisión administrativa que les permita enfrentar los requerimientos del debate público sin caer en "extralimitaciones", pues la legislación de la radio comunitaria en Colombia establece que las emisoras comunitarias no pueden participar "en política", y según la percepción de los alter comunicadores del sur del país, buena parte del debate sobre la paz en Colombia es eminentemente político:

Nosotros vamos a tratar ese tema en el comité técnico del centro de producción, eso ya se agendó. Tenemos también una reunión con el Ministerio de Cultura para que nos den algunas directrices de por dónde tocar el tema, sin que vayamos a tener problemas, porque esos temas son difíciles de tocar en muchos sentidos... (Conversación personal con Líverman Rengifo de Ocaina estéreo, julio de 2014)

Lo que se entrevé, finalmente, es que las comunidades no se ven vinculadas con las discusiones en torno al posconflicto, lo que genera un distanciamiento conceptual y práctico frente a la deliberación pública y a los compromisos que podría ameritar la participación de las comunidades y de los alter medios en su implementación, sobre todo 
en aquellos territorios donde aún se evidencia la presencia de actores armados.

Elemento de análisis 6: "Así haya firma de los acuerdos de paz, aqui todo va a seguir lo mismo..." En consecuencia con el elemento anterior, en los territorios de influencia del conflicto armado se reitera insistentemente por parte de los ciudadanos que "aquí todo va a seguir lo mismo”. Más allá de un distanciamiento conceptual con las nociones de posconflicto o pos acuerdo, las evidencias dramáticas del ejercicio de la violencia en el marco del conflicto armado y las experiencias fallidas de procesos de paz anteriores ${ }^{9}$, llevan a pensar a los ciudadanos que el conflicto tendrá continuidad.

Nosotros hemos propuesto en la agenda de la junta de programación de la emisora tocar el tema del posconflicto, incluso en las temáticas del comité técnico del centro de producción también está agendado. Sin embargo, nosotros hemos hecho un trabajo de diagnóstico en las comunidades donde hay presencia de grupos armados, y lo que ellos han manifestado es que así haya firma [de los acuerdos de paz con las Farc-ep] aquí va a seguir lo mismo, entonces ese el gran temor de uno tocar este tema antes de los resultados, porque ellos allá pueden firmar lo que sea, pero nosotros somos otro cuento y acá las condiciones van a continuar lo mismo... (Conversación personal con Líverman Rengifo de Ocaina estéreo)

Otro factor que incide en el "descrédito" del posconflicto, es la existencia de otros múltiples conflictos frente a los cuales no se avizoran

9 Los esfuerzos de la paz en Colombia desde la segunda mitad del siglo xx, representados en procesos motivados por los gobiernos, han sido: Amnistía a las guerrillas liberales (1953); Plebiscito Frente Nacional (1957); Pacto de la Uribe - Farc (1984); Diálogo nacional M-19, EPL, la ADO (1984); Procesos de paz con el M-19, EPL, PRT y Quintín Lame (1989 - 1991); Diálogos de Tlaxcala y Caracas (1990, 1991); Proceso de paz con la CRS (1994); Proceso de paz del Caguán (1998); Rondas de La Habana (2005); Proceso de paz AUC (2008); Diálogos de La Habana (2012). (Con información tomada del CMPR, s.f.) 
soluciones prontas. Al contrario, políticas nacionales agenciadas por los gobiernos, como las denominadas "locomotoras del desarrollo" (la locomotora minero energética, los monocultivos, los proyectos viales de envergadura internacional como la "Troncal de la selva", etc.), fomentan en las gentes de estas regiones incredulidad frente al proceso de paz, por cuanto estos proyectos legalizados por los gobiernos sin la legitimación de las comunidades, está generando nuevos conflictos que, además, producen enfrentamientos violentos entre las comunidades y la fuerza pública, por cuanto las comunidades reclaman su autonomía en la definición de los proyectos a implementar en las regiones y, en casos específicos como el de las comunidades indígenas, se reclaman los procesos de consultas previas legales y legítimas para el desarrollo de actividades en sus territorios.

Hacemos programas que motivaran a la gente para que no venga a entregar tan fácil la zona. Por ejemplo, nosotros ya estamos saliendo de lo que era el problema de la petrolera, que quisieron venir a operar en nuestro territorio sin consulta previa ni nada. $\mathrm{Y}$ nosotros mostramos desde la emisora cómo la gente debería exigir lo que era un dialogo con ellos [con la petrolera], para que respetaran nuestra posición como indígenas. [...] Y por medio de la emisora estuvimos tratando esos temas, pero como se nos dañó [los equipos] ahí quedamos... (Conversación personal con Alexander Becerra de Ingakuna estéreo)

Elemento de análisis 7: Con acuerdo o sin acuerdo de paz, las comunidades y sus procesos alter comunicativos tienen que seguir en la lógica de la negociación con los actores de los conflictos. Los procesos de negociación en realidad no son nuevos para las comunidades y experiencias alter comunicativas que habitan zonas de conflicto. La negociación es un factor permanente en el relacionamiento entre las comunidades, y de las comunidades con los actores de la guerra.

De cara al proceso de negociación en La Habana es poco lo que estas comunidades sienten y piensan haber negociado. Los campesinos y los indígenas preguntan sobre quién los está representando. Los gestores de la alter comunicación no consideran que sus intereses 
estén vinculados con la agenda, y como gestores de alter medios no saben cómo y hasta dónde relacionar la agenda de negociación institucional de la paz con las agendas mediáticas.

Así, las negociaciones que agencian estas comunidades están inscritas con los problemas "reales" de la gente, del territorio y del conflicto, de los conflictos. Porque más allá de los acuerdos que se logren en La Habana, de lograr la paz con las Farc-ep, la realidad de estas comunidades dice que los actores armados están en sus territorios, y que, se quiera o no, hay que interlocutar con ellos.

Al tiempo, las comunidades y, en particular, los gestores de la alter comunicación, como líderes, tienen una vocación que los lleva a intervenir en los asuntos públicos, incluso en aquellos relacionados con el conflicto armado. Esta vocación los lleva a reivindicar y promover la participación como estrategia de deliberación pública y democrática. No en vano desde las esferas alter comunicativas se busca informar para participar, para decidir, para intervenir:

Nosotros estamos muy lejos de donde se está negociando y entonces queremos promover que la gente sienta que también hace parte de esa negociación, y que de alguna manera, así los de acá se desmovilicen o no, tenemos que estar en esa tónica de ese proceso de negociación, tenemos que estar en la lógica de la paz. (Conversación personal con Líverman Rengifo de Ocaina estéreo)

Frente a este conjunto de factores, finalmente se puede señalar que estos elementos de análisis relacionados con el conflicto armado y con la paz, trasversan los procesos de producción de contenidos alter comunicativos. Estos elementos analíticos orientan perspectivas interpretativas que sobre la guerra y la paz formulan los gestores de la alter comunicación en zonas de conflicto. Y este sistema de representaciones sobre la guerra y la paz determina, a su vez, acciones discursivas constitutivas de los procesos de producción mediática.

Por ejemplo, cuando Waira Jacanamijoy, de Ingakuna estéreo, señala que "solo se habla de lo que se conoce", esta situación orienta los sistemas de producción de contenidos mass mediáticos, por cuanto 
constituye una orientación no solo para la vida del sujeto sino para la política editorial del proceso alter comunicativo.

Del mismo modo, los elementos de análisis propuestos contribuyen en el establecimiento de un sistema de representación situado de la paz y el conflicto, sistema surgido de los contextos singulares que enfrentan las experiencias alter comunicativas y que les proponen (y a veces les imponen) determinaciones a sus acciones de definición, producción y circulación de contenidos.

De este modo, señalamos cómo el contexto de la guerra y las apuestas por la paz intervienen en los procesos de producción alter comunicativa, estableciendo un ecosistema comunicativo e informativo que no necesariamente podría ser interpretado a la luz de las categorías y enfoque analíticos, con los que se exploran otras experiencias (las de los medios masivos hegemónicos, por ejemplo), en otros contextos.

\section{Trazados de la alter comunicación en zonas de conflicto armado: características, incidencias, repercusiones y respuestas}

En este apartado final se establecen una serie de contextos que han incidido en la configuración del sistema de representaciones a partir del cual se interpreta localmente el conflicto y la paz, en tono alter comunicativo. Como ya se ha señalado, estos sistemas de representaciones, en tanto sistemas socialmente contextualizados, formulan significaciones y producciones discursivas particulares, que interpretan los acontecimientos con el tono de su propia realidad.

A partir de lo anterior, y teniendo en cuenta que "la significación de una representación social está entrelazada o anclada siempre en significaciones más generales que intervienen en las relaciones simbólicas propias al campo social dado" (Doise citado por Abric, 1994, pp.15-16), es pertinente identificar en este análisis, las características, incidencias, repercusiones y respuestas que configuran los contextos de las significaciones que frente al conflicto armado, el posconflicto y 
la paz han venido configurando los alter comunicadores que trabajan en zonas de conflicto.

Miremos entonces, de manera esquemática, cómo "el saber práctico de sentido común —según le llama Moscovici- permite a los actores sociales adquirir [y formular] conocimientos e integrarlos en un marco asimilable y comprensible para ellos, en coherencia con su funcionamiento cognitivo y con los valores a los que se adhieren" (Abric, 1994, p.15); es decir, cómo las experiencias de alter medios en zonas de conflicto definen marcos de referencia comunes y contextualizados, que les permiten interpretar la realidad social que, posteriormente será comunicada e informada a las comunidades desde el escenario mass mediático local.

\section{Características de la alter comunicación en zonas de conflicto armado (CA)}

Los alter medios engloban la complejidad del conflicto social y armado: como expresiones comunitarias, los alter medios no son ajenos a las condiciones de desarrollo local del conflicto armado. Se ven inmersas en una realidad que es profundamente problemática y violenta, hasta el punto de que sus gestores, por efecto de su liderazgo, se ven amenazados de manera permanente por los actores armados. Pero los gestores de la alter comunicación no inscriben su ejercicio solamente en el relato de los acontecimientos de la guerra. Por el contrario, formulan una mirada panorámica del contexto, lo que les permite abordar temáticas diversas, muchas de ellas relacionadas con expresiones de paz, en el amplio espectro de las esferas públicas locales.

Por otro lado, los alter medios se han constituido también en respuesta civil a los rigores de la guerra. Se han convertido en escenarios de deliberación pública, en defensores de derechos humanos, en veedores de la acción institucional, en gestores de procesos comunitarios, más allá de la misma comunicación. Por supuesto su labor no está exenta de dificultades y contradicciones, de cooptaciones e incompatibilidades, y por esto mismo, en razón de sus fortalezas y debilidades, estas experiencias ciudadanas engloban la complejidad del conflicto social y armado. 
Desde la alter comunicación se valoran críticamente los contextos, actores, territorios y estrategias del CA: las experiencias participantes en el estudio valoran el impacto y los daños que el conflicto armado ha generado en sus comunidades. Esto los lleva, en el marco de unas mínimas responsabilidades sociales y comunitarias, a formular miradas críticas sobre el contexto problemático en el que se desarrollan sus acciones.

Para el caso de los alter comunicadores, la gestión comunicativa no se queda en las denuncias (entre otras cuestiones porque difícilmente pueden hacerlas), sino que transita por el análisis, la deliberación y el debate público, y acude a la creatividad, a las artes, a la pedagogía, para poder tramitar públicamente contenidos que, en un manejo "tradicional" 10 de la información, serían imposibles de publicar. En este sentido, las experiencias alter comunicativas intentan proponer una mirada panorámica de los acontecimientos y, en la medida de su conocimiento de las condiciones propias de los territorios y las dinámicas de las comunidades, articulan en sus análisis los contextos, actores y estrategias que inciden en el desarrollo de los hechos.

En los alter medios se aplican criterios editoriales reivindicativos: el discurso reivindicativo se entiende como una reclamación del papel que deben jugar las comunidades en los procesos comunicativos e informativos. Frente a la crisis de la práctica comunicativa ejercida por los medios masivos de comunicación en lo que tiene que ver con el tratamiento del conflicto armado, las comunidades, por la vía de los alter medios, se apropian de los recursos comunicativos de los que disponen y generan nuevos-otros relatos, más vivos, más profundos y con conocimiento de causa, para dar trámite público a los temas relacionados con la guerra y, sobre todo, con las expresiones de paz.

10 Cuando hablamos de un manejo "tradicional" de la información, nos referimos a la aplicación, en la producción periodística, de técnicas e instrumentos clásicos del periodismo moderno, como la técnica del "lead", que impone responder el qué, quién, cuándo, cómo y dónde como insumo básico de la información. Para el caso de la alter comunicación en zonas de conflicto, estos esquemas representan muchos límites que deben ser superados para profundizar, creativamente, en la lógica de los acontecimientos. 
En los alter medios se revelan las "intenciones" informativas: el contrario de los medios masivos y comerciales de comunicación, que dicen sustentar sus ejercicios informativos en criterios como la objetividad y la neutralidad periodística, los alter comunicadores revelan sus intenciones informativas a la hora de integrar sus discursos en las esferas públicas locales. En consecuencia con el punto anterior, la mirada reivindicativa de los procesos alter comunicativos (aquellos donde la comunidad y sus respuestas cotidianas al conflicto se constituyen en centro, aquellos donde la voz de los ciudadanos es reconocida como fuente fundamental, aquellos donde se ejerce una pedagogía informativa y del contexto que posibilita ampliar los referentes para interpretar las realidades del territorio), posibilita la toma de posiciones frente a las dinámicas del conflicto y los actores armados que lo imponen indiscriminadamente a las poblaciones.

Revelar las intencionalidades del proceso alter comunicativo genera, por supuesto, riesgos importantes para los alter comunicadores y sus "comunidades de base". Pero los procesos han sabido tramitar estos riesgos, posicionando su ejercicio en las esferas públicas locales a partir del tratamiento responsable de la información, y a través del uso de herramientas pedagógicas y comunicativas que vinculan a las audiencias en la reflexión del conflicto y en la acción desde las culturas de paz. De este modo, los alter medios se posicionan como actores de paz, la discuten y la agencian socialmente, toman posición por ella, en contra de la violencia como recurso de relaciomaniento social.

Desde la alter comunicación se proponen otras formas y estrategias de producción comunicativa: la producción alter comunicativa supera la estrategia puramente mediática a la hora de tratar temas relacionados con el conflicto armado y la paz (entre otros múltiples temas de interés comunitario). Los medios comunicativos son entendidos de manera amplia, pues si bien es cierto existe una vocación por implementar la radio y, en menor medida para el caso de las zonas rurales afectadas por el conflicto, el audiovisual, la prensa y tecnologías como la Internet, las experiencias también acuden a otros modos de expresión como el teatro, la música, el deporte, la asamblea, etc., estrategias 
efectivas a la hora de compartir y discutir información importante para el desarrollo de las esferas públicas locales.

Las dinámicas del conflicto imponen a los alter comunicadores ser creativos. Frente a los escenarios tácitos e implícitos de censura que se imponen a las comunidades, los alter comunicadores funcionan como agentes de la creatividad, de la producción de mensajes originales que cumplen objetivos informativos, pero no se quedan allí: también pretenden formar, inquietar para la acción y la deliberación pública, para la participación.

Son múltiples las dificultades que se enfrentan:

Nosotros quisiéramos hacer mucho más para la radio comunitaria, pero lastimosamente las condiciones no están dadas para hacerlo porque hay temas que no se pueden tocar, y por eso se los trabaja más a través de los trabajos de campo que hacemos, en los foros comunitarios que hacemos, ahí es donde tocamos estos temas, pero no por la radio, porque no se puede. Y bueno, con estas estrategias [foros, encuentros deportivos, recorridos territoriales, espacios de formación, implementación de proyectos productivos, etc.] las comunidades nos siguen respaldando en el trabajo que venimos haciendo". (Conversación personal con Líverman Rengifo de Ocaina estéreo, 5 de julio de 2014)

Así, y en paralelo a las estrategias que impone el silencio en la guerra, surgen otras que son definidas por los alter comunicadores y sus comunidades, para hacer frente al cerco informativo que pretenden imponer los armados.

Desde la alter comunicación se promueve la participación de las comunidades: para que las estrategias alter mediáticas funcionen, deben contar con un amplio y decidido apoyo de las comunidades que les sirven de referencia. Un proyecto alter comunicativo local no tiene sustento alguno si no es validado, apoyado, vinculado y discutido con las comunidades, menos en situaciones de conflicto armado donde, por efectos del mismo accionar de la guerra, las comunidades tienden a fragmentarse. 
Frente a esa fragmentación impuesta, la alter comunicación funciona como estrategia catalizadora y de integración. La alter comunicación facilita la recomposición de las confianzas, en tanto facilita espacios de encuentro para la conversación social y para la memoria. Los espacios de encuentro que facilitan los alter medios son, de manera fundamental, de carácter simbólico: permiten el encuentro con la historia, con el recuerdo, con los sueños arrebatados, con las posibilidades de acción para superar las crisis.

Si "las lógicas de la guerra impusieron la desconfianza, el silencio y el aislamiento, y deterioraron valores sociales fundamentales como la solidaridad, la participación y la reciprocidad, (...) valores [que] garantizan la seguridad, el desarrollo personal y resultan fundamentales para la convivencia y la cohesión social” (CNMH, 2013, p.274), la alter comunicación contribuye en la reconfiguración de estos valores comunitarios, porque permite espacios de encuentro, restringe la propagación de rumores y señalamientos, promueve la discusión pública.

En esta perspectiva, la participación de las comunidades en los procesos alter comunicativos no se entiende solamente como la posibilidad de integrarse activamente en la producción de contenidos. Se entiende, más bien, como un escenario social que posibilita a las comunidades y a los sujetos la recuperación de sus facultades públicas, la reivindicación social del sujeto histórico colectivo que incide en el devenir público de su comunidad.

\section{Incidencias del conflicto armado en la producción de contenidos}

En el marco del conflicto armado colombiano se imponen contextos que restringen a los alter comunicadores la formulación de alternativas para la re-semantización informativa y comunicativa de la guerra. Son múltiples los factores que intervienen en la implementación de nuevos-otros modos de contar los acontecimientos relativos al conflicto armado y a la paz, entre los que se destacan: la censura, la 
auto censura ${ }^{11}$, la violencia directa ${ }^{12}$ (ejercida por actores armados legales e ilegales), la violencia indirecta ${ }^{13}$, el déficit de sostenibilidad económica de los medios y su consecuente cooptación por parte de organizaciones y actores políticos y económicos, la regulación de la pauta publicitaria sobre la base de los contenidos publicados y, finalmente, el acoso judicial ejercido sobre los trabajadores de los medios informativos.

Estos factores constituyen unos referentes generales de análisis, que consideramos necesario revisar:

- Censura directa: la censura, entendida como la intervención que se practica sobre el contenido o la forma de una información, atendiendo a razones ideológicas, morales, económicas, culturales o políticas ${ }^{14}$, es un factor que incide en los procesos informativos de los alter medios en regiones de conflicto armado. La censura directa se impone, fundamentalmente, por la vía de las amenazas, los atentados y las persecuciones a productores de alter medios en las regiones. Como se ha señalado, en las zonas afectadas por la guerra "hay temas que no se pueden tocar", temas relacionados con los actores armados y sus acciones bélicas, pero también con la cooptación que estructuras criminales de diferente índole han hecho

11 Que en muchos casos es expresión de la censura ejercida por propietarios, directores y editores de los medios, es decir, una censura "desde adentro".

12 Violencia directa representada en asesinatos, amenazas y agresiones de facto, ejercida desde los actores armados participantes en el conflicto (institucionales e ilegales) hacia los comunicadores y periodistas comunitarios, alternativos y populares que desarrollan sus labores en zonas de conflicto.

13 Ejercida por actores armados, dirigentes políticos y económicos, representada en intimidación y "siembra del miedo", y la ejercida por los mismos medios de comunicación en medio de las dinámicas laborales relacionadas con la desprotección frente al ejercicio de su labor.

14 La base de esta definición, que ha sido ajustada al tema informativo, es tomada del Diccionario de la Real Academia de la Lengua Española. Ed. 2001, versión web. 
de los recursos públicos y de las estructuras institucionales en las regiones.

Si bien es cierto, los índices de agresiones (amenazas, asesinatos, etc.) en contra de comunicadores en el país ha disminuido en la última década, informes como los de la Fundación para la Libertad de Prensa (FLIP) evidencian que los factores de la violencia siguen incidiendo en los procesos de producción y circulación de información, en niveles alarmantes: “... esa aparente mejora en el estado de seguridad, no coincide con los testimonios de muchos comunicadores que, especialmente en las regiones, aseguran que si bien ya no matan periodistas, las condiciones para hacer periodismo no necesariamente han mejorado del todo" (FLIP, 2011, p.7).

Para revertir este factor, los alter comunicadores señalan que se requiere del establecimiento de un debate público amplio por parte de los productores de medios (masivos y alternativos), de los ciudadanos y las instituciones (públicas y privadas), un debate que dé cuenta permanente de la situación que viven los comunicadores en las regiones, y que interpele los modos como se interpretan los contextos y las problemáticas sociales relacionadas con el conflicto colombiano, a partir de reconocer que "el lenguaje es lo que dice [sobre el conflicto], pero también lo que destierra" (Serrano, 2009, p.52).

- Autocensura: si la censura la definimos como la intervención que realiza un agente externo sobre el contenido o la forma de una información, la autocensura se debe entender como el arbitraje o la vigilancia que el propio comunicador hace sobre los contenidos que produce, motivado por circunstancias ajenas a él (sean estas políticas, de seguridad, económicas, ideológicas, etc.). Este tipo de censura se expresa de múltiples formas, tal y como lo señala la FLIP en su informe anual sobre el estado de la libertad de prensa en Colombia (2011): "muchos periodistas, como mecanismo de supervivencia en sus medios y regiones, evitan tocar ciertas problemáticas o no ahondan en sus investigaciones para evitar ser agredidos. Prefieren leer 
comunicados oficiales sin contrastar fuentes para evitar problemas..."15 (FLIP, 2011, p.13).

La autocensura no es exclusiva de los alter medios. Los medios masivos, comerciales, hegemónicos de información no son ajenos a esta realidad; por el contrario, este es un factor inherente a sus prácticas informativas, debido a sus condiciones de surgimiento, conformación y desarrollo, que se alinean con sectores hegemónicos del poder político y económico nacional.

Para el caso de los alter medios, la situación, en un número importante de casos, es diferente: su surgimiento depende de circunstancias que superan filiaciones político ${ }^{16}$-económicas hegemónicas e, incluso, este tipo de dependencias son fermento para su surgimiento y establecimiento en comunidades que quieren dar respuesta a los procesos de desinformación que sobre ellas se implementan. Esto no quiere decir que a nivel de los medios alternativos no se apliquen criterios relacionados con la autocensura, como tampoco se quiere decir que todas las prácticas informativas de los medios masivos hegemónicos se dirijan a ella.

La autocensura referida a los alter medios es producto de intimidaciones, amenazas y asesinatos. Una larga trayectoria de violencia sobre los comunicadores colombianos, sobre

15 Un balance preliminar de estos atentados al "derecho a la palabra" en Colombia lo ofrece, para el año 2013, la FLIP, que en su informe Protestas: sin garantías para cubrir señala que: "En 2013 se registró un total de 123 agresiones directas contra la prensa, que dejaron un total de 194 víctimas. (...) Buena parte de las agresiones contra la prensa ocurrieron en el cubrimiento de las protestas prolongadas que vivió el país durante 2013, principalmente mediante la obstrucción al trabajo periodístico. En total, 44 periodistas resultaron afectados durante las manifestaciones." (FLIP, 2013, p. 8)

16 Nos referimos aquí a filiaciones políticas partidistas. Damos por sentado que los medios alternativos, populares y comunitarios tienen un profundo significado político, entendido este como la posibilidad que se establece desde el espacio comunicativo alternativo de intervenir en la construcción de la esfera pública, sin que ello implique, per sé, identidades partidistas, aunque las haya. 
todo por aquellos que realizan sus labores por fuera del régimen comunicativo hegemónico, confirman a la autocensura como estrategia de sobrevivencia: "esta censura instaurada que se exhibe de muchas formas, (...) perjudica sobre todo a la ciudadanía que deja de conocer información de interés público, el sustento esencial de su toma de decisiones. Temas relacionados con corrupción, mafias locales u orden público, se evitan”, señala la FLIP (2011, p.13).

- Imposición de agendas informativas: un factor incidente en los procesos alter comunicativos en zonas de conflicto tiene que ver con la imposición, por parte de los actores armados, de temas y problemas a tratar en las agendas informativas. Reconociendo la importancia de los alter medios en las regiones, los actores armados procuran, como parte de sus estrategias de guerra, apropiarse de los recursos materiales y simbólicos que las comunidades han establecido para su funcionamiento e interlocución.

Lo que se genera es una cooptación de las agendas públicas representadas en las agendas de los alter medios, con todo el impacto que esta situación genera en las comunidades: se configuran visiones unilaterales de los hechos, se distribuyen contenidos que niegan la diversidad, se velan informaciones relacionadas con los recursos públicos, que por lo general son dispuestos para los intereses reivindicativos de los diferentes actores armados, se privatiza la opinión pública, se imponen "temas, personajes y hechos que luego serán de dominio público, situación que conduce a un proceso directo de formación de la opinión pública en una sociedad" (Botero, 2007, p.207).

- Desviación de responsabilidades: con la imposición de las agendas informativas, los actores armados garantizan algo de impunidad. La desviación de las agendas públicas promueve la desviación de la mirada sobre los responsables de los actos criminales, de corrupción y la politiquería. Si en Colombia existen dificultades a la hora de ubicar los responsables de los delitos, y si en muchas ocasiones ni siquiera la sociedad 
tiene conocimiento de estos delitos, es porque aquellos dispositivos sociales (escuela, medios de comunicación, partidos políticos, entre otros) que se han ideado para hacer públicos temas, personajes y hechos, no funcionan.

Y no funcionan, entre otras cuestiones, por lo que se ha venido mencionando: existe todo un sistema dispuesto para coartar los derechos ciudadanos, entre ellos los relacionados con la comunicación, la expresión, la opinión y los medios, donde la censura, la autocensura, la imposición de agendas, el ejercicio de la violencia, la cooptación, déficit de sostenibilidad económica y el acoso judicial, entre otros fenómenos, evitan la imputación efectiva de responsabilidades.

- Estigmatización y criminalización: como último factor que incide, de forma negativa, en la definición, producción y circulación de contenidos informativos en zonas de conflicto, reseñamos los procesos de estigmatización y criminalización que se ejerce por parte de actores armados e institucionales sobre los alter comunicadores en las regiones. Esta ha sido una estrategia impulsada e implementada, sobre todo, aunque no exclusivamente, por sectores institucionales que ejercen funciones de policía y de justicia.

Los señalamientos a la prensa independiente, a los actores alter comunicativos, generan múltiples resultados: amenazas, asesinatos, desplazamientos forzados, acoso judicial, encarcelamientos, desprestigio en las comunidades de referencia... La estigmatización y criminalización tiene como finalidad restringir el accionar de la alter comunicación, así como el impacto que sus informaciones y procesos sociales generan en las comunidades.

El impacto de estos factores demuestran la importancia que tiene la alter comunicación en zonas de conflicto, por cuanto se ha instituido como espacio ciudadano para la deliberación pública, a partir de la implementación de procesos que en medio de todas las dificultades, siguen promoviendo, así sea sutilmente, espacios ciudadanos reivindicativos de la paz, de los derechos humanos y de la participación. 
Los señalamientos persisten, con todo el impacto que esta situación genera en los gestores de la alter comunicación, como lo señalaba Waira de Ingakuna estéreo: “Cuando estaba empezando a trabajar en la radio yo aparecí amenazada, en el 2003, como auxiliar de la guerrilla. Me ha demandado algún NN aquí en Bogotá, en la época de Uribe” (Conversación personal con Waira Jacanamijoy de Ingakuna estéreo).

Parte de la estrategia tiene que ver con lograr el desprestigio de los gestores y líderes comunitarios, para disminuir su credibilidad y la de sus acciones frente a la comunidad. Para el caso del acoso judicial, producto en buena medida de la estigmatización y criminalización, este se da cuando "una persona abusa de las demandas judiciales con el fin de censurar el libre trabajo periodístico y su objetivo no tiene que ser la condena del periodista, basta con obligarlo a tener que responder frente a los jueces, y someterlo a un proceso extenso, desgastante y engorroso...” (FLIP, 2012, p.18). Acciones de este tipo pueden ser consideradas como estrategia para implementar nuevos escenarios de censura informativa, pues conduce, en muchos casos, a que el comunicador deje de hacer investigaciones sobre los temas, hechos y personas que movilizan a pseudo investigaciones en contra de los alter comunicadores.

\section{Repercusiones comunicativas del conflicto armado en la esfera pública local}

Establecidas las incidencias que el conflicto armado tiene sobre la acción alter comunicativa, miremos ahora las repercusiones que la guerra genera en los procesos alter comunicativos locales del sur del país. Cuando hablamos de repercusiones, nos referimos a los "impactos negativos" que el conflicto genera en los procesos de sociabilidad comunicativa y en las esferas públicas de las comunidades y territorios de influencia de las experiencias.

Reconocemos, por supuesto, que en paralelo a los impactos negativos, los actores comunicativos formulan acciones creativas y de resistencia a los embates del conflicto. Estas cuestiones las veremos 
más adelante, en el apartado de las respuestas locales a los escenarios conflictivos. En este apartado, insistimos, revisaremos los aspectos negativos que repercuten en el trabajo alter comunicativo, sus impactos y las repercusiones en los escenarios público comunicativos locales.

- Restricción de acceso a argumentos para participar cualificadamente en el debate público del conflicto armado: los contextos de conflicto armado no posibilitan que los ciudadanos accedan al conjunto de argumentos que les permitan participar cualificadamente en el debate de los temas públicos, entre ellos el mismo conflicto armado, que se convierte, en este sentido, en una vivencia frente a la cual no se permite la reflexión. Lo que buscan los alter comunicadores (junto con otros procesos ciudadanos) en este escenario de restricción del debate público del conflicto en la esfera pública local, es "hacer público lo público", devolver a las comunidades la posibilidad y la capacidad de deliberar racional y sensitivamente sus conflictos, sus memorias, sus vivencias, sus pérdidas.

- Versión unilateral del conflicto armado: otra de las repercusiones del conflicto armado en la esfera pública local tiene que ver con la instalación de lo que podríamos llamar un consenso inducido, es decir, la instauración social de una mirada hegemónica unilateral del contexto, propiciada por el actor armado prevaleciente en la zona. El consenso inducido restringe no solo la deliberación de los asuntos de la guerra, sino que en general niega la pluralidad y la diversidad constitutiva de las comunidades, en el plano político-ideológico, pero también en lo relacionado con la cultura, con la economía (los actores del conflicto imponen también modos económicos particulares), con los sistemas de relaciones, con la sexualidad, etcétera.

- Los medios de comunicación se convierten en escenario de disputa: en general los dispositivos de producción y re-producción simbólica de la sociedad han sido materia de disputa por parte de los diferentes actores sociales en busca de hegemonía. Para el caso de los medios de comunicación en zonas 
de conflicto, ellos funcionan como dispositivos estratégicos en la medida que facilitan la distribución y el posicionamiento de discursos apologéticos.

De los medios de comunicación se busca o su apropiación o su desaparición. No se acepta de ellos ninguna neutralidad, y al tiempo que se combate por el posicionamiento estratégico en el territorio, también se busca el posicionamiento ideológico y cultural. Para estos fines los medios de comunicación son fundamentales, en tanto posibilitan el posicionamiento público de intereses propios de los actores armados. Con esta cooptación o con la desaparición de los alter medios, los ciudadanos se retraen más fácilmente a la esfera doméstica, con lo cual se les priva, se les desprovee de su capacidad de participar activamente en la resolución del conflicto que les ha sido impuesto.

- Confiscación de la libertad de expresión por parte de todos los grupos armados: la libertad de expresión, consagrada en el artículo 20 de la Constitución Política de Colombia, es uno de los derechos más afectados por el conflicto armado.

La libertad de expresión es una condición necesaria para que el ser humano se desarrolle plenamente en sociedad. (...) Pero no solo se busca la realización del individuo con la libertad de expresión, también [se busca] la realización del Estado social de derecho, democrático, participativo y pluralista. El ser político se desarrolla en un Estado democrático, solo si puede expresarse libremente, difundir su pensamiento, recibir información veraz e imparcial y, si es el caso, fundar medios de comunicación que no podrán por lo tanto ser monopolio exclusivo de nadie, ni aún del Estado... (Atehortúa, s.f., 29)

En sociedades donde la garantía de los derechos es tan restringida, la noción de libertad de expresión tiene muy pocos debates. Son los alter comunicadores quienes, en el ejercicio de sus procesos con las comunidades, promueven una discusión sobre lo que implica el derecho a decir y a decirse. No pueden ser otros los que pronuncien la palabra de las 
comunidades, menos cuando esos otros mantienen a la comunidad en permanente zozobra mediante el ejercicio de la violencia. Pero son los actores armados los que han determinado, durante buena parte de la historia reciente del país, lo que la gente puede o no puede decir, cuándo y cómo decirlo. La alter comunicación ha servido, en este contexto, como catalizador social que promueve la recuperación de los derechos a la comunicación de las comunidades afectadas por el conflicto, y han buscado la restitución de estos derechos, entendiendo que la libertad plena del sujeto pasa, de manera fundamental, por su derecho a expresar con libertad y responsabilidad lo que piensa y siente.

- Restricción de espacios de encuentro para el debate público: asesinado el padre Alcides Jiménez, en septiembre de 1998, la población de Puerto Caicedo y en general el departamento del Putumayo perdió uno de sus líderes más importantes. La comunidad también perdió la posibilidad de reivindicar los espacios de encuentro que había construido para gestionar acciones en favor de sus intereses. Así, además de los crímenes sobre la vida y los daños materiales y morales, el conflicto también genera daños socioculturales y políticos,

que se refieren a las lesiones y alteraciones producidas en los vínculos y relaciones sociales. (...) Estos daños, que afectan colectivamente a las comunidades, son consecuencia de la prohibición explícita o del impedimento y las dificultades que experimentaron las personas y las comunidades para mantener sus relaciones, vínculos e intercambios, con los cuales participaban de la construcción de la identidad grupal y colectiva... (CMPR, 2013, p.272)

Una de las características de este tipo de daños es el despoblamiento de los espacios públicos de encuentro, que son factor primordial para el desarrollo de la esfera pública. Los espacios públicos son escenarios de encuentro para la deliberación de los asuntos públicos, ellos son condición ineludible para la participación real y para el agenciamiento de los puntos 
de vista que componen la esfera pública plural. Sin el espacio público se limita la participación, se restringe la posibilidad de discutir las diversas posturas, algunas de ellas antagónicas, que constituyen lo social. Por esto, una de las funciones fundamentales de los alter medios ha sido la de la re-apropiación y la re-escenificación de aquellos lugares donde la guerra ha dejado sus marcas, limitando la presión de los armados y la instauración del miedo, la desconfianza y el silencio como indicadores del relacionamiento social comunitario.

\section{Respuestas locales a la "lógica informativa" del conflicto armado}

Como respuesta a las dinámicas del conflicto, a sus imposiciones, incidencias y repercusiones, los actores de la alter comunicación, en conjunto con sus comunidades, han venido generando una serie de respuestas que contribuyen en la recomposición de las esferas públicas locales. Estas respuestas atienden problemas comunitarios, como la recuperación física y simbólica de los espacios públicos para la deliberación ciudadana, y problemas propios del campo de la comunicación, como la "descentralización de la figura y el papel del periodista”. Para finalizar este capítulo, miremos puntualmente algunas de estas respuestas:

- Los medios como lugares de encuentro para el debate público del conflicto armado: frente a la imposibilidad de actuar en los espacios públicos vedados por los actores armados, y frente a la clausura de los espacios de encuentro comunitario, los alter medios se erigen como nuevos-otros espacios significativos de reunión y deliberación pública. Los alter medios se han encargado de instalar nuevos espacios, nuevos dispositivos de relacionamiento y, por extensión, nuevos-otros sistemas de relacionamiento y representación de lo social, lo político y lo cultural, en perspectiva de la paz y los derechos humanos. Desde la alter comunicación se formulan nuevas interacciones comunicativas que contribuyen 
en la recuperación de los espacios comunitarios que reivindican lo común en las relaciones entre sujetos.

- Descentralización de la figura del periodista responsable de informar (todos informamos): con el posicionamiento de un tipo de comunicación surgida del interés y la iniciativa de las mismas comunidades, la figura del "comunicador", del “periodista", se descentra. Son los mismos actores comunitarios: el campesino, el estudiante, el comerciante, el líder comunitario, las mujeres, en fin, los mismos ciudadanos, quienes contribuyen en la producción informativa y en la reflexión pública de los asuntos comunes.

Al contrario de los "grandes medios" que legitiman permanentemente la figura del periodista como el "orientador de la opinión y la información”, los alter medios distribuyen socialmente la función de comunicar. Esto no quiere decir que la figura "del comunicador" se diluya en la comunidad, ya que los gestores de la comunicación son perfectamente identificables. Lo que se señala es que la función del comunicador cambia, este se convierte ahora en gestor de contenidos, en generador de procesos comunitarios que alientan la participación comunicativa de los sujetos. El comunicador no concentra en sí el proceso, sino que lo agencia socialmente, con la intención de distribuir las responsabilidades que implica la deliberación pública, más allá de la mirada exclusiva de los problemas públicos que formulan los expertos y los especialistas. Ahora es la comunidad en su conjunto la que contribuye en el debate, participa, comunica.

- Abordaje "no manifiesto" de la incidencia local del conflicto armado: este es un punto interesante, ya que frente a la imposibilidad de producir y tramitar directamente contenidos relacionados con el conflicto armado (con hechos y personajes) los alter comunicadores han creado estrategias que les posibilitan "hablar del conflicto sin hablar de él". Por ejemplo, tratando temas ambientales responden a problemas territoriales y atienden conflictos que son "fuente" del conflicto armado contemporáneo: la minería, el petróleo, la coca. 
Para el caso de las emisoras indígenas como Ingakuna, buena parte de la producción atiende problemas relacionados con "el cuidado de sí mismo", con lo cual atienden problemas relacionados con la defensa del territorio, con la autonomía, con la defensa de las tradiciones y la cultura. Lo que se configura es una agenda comunicativa alterna que, en lo profundo, atiende los problemas estructurales de la comunidad: el cuidado de los recursos, la defensa de los derechos humanos, la reivindicación de las solidaridades como criterio de relacionamiento social, el reconocimiento de la cultura y las artes como estrategia para enfrentar las dinámicas del conflicto, la recuperación del espacio público y mediático como posibilidad de recuperación de la voz propia, etc.

- Cuestionan la propiedad de los medios masivos y gestionan la creación de los propios medios: con el tiempo y la experiencia, los alter comunicadores han entrado en el debate global, en tono local, de los medios de comunicación, su propiedad y la función socio política que cumplen en el mundo contemporáneo. Desde su lugar comunitario, critican los sistemas de representación y significación que agencian los medios sobre las comunidades locales y sobre los territorios, así como la estructura comunicativa e informativa fomenta procesos de estigmatización y criminalización de las poblaciones que se encuentran por fuera de las centralidades del poder y la economía.

En paralelo, los alter comunicadores hacen frente al cerco informativo del régimen hegemónico mediático, al fundar sus propios medios y sus propias estrategias de producción y acción comunicativas, estrategias que ponen en cuestión la propiedad de los medios de producción simbólica de la que se han apoderado los oligopolios mediáticos a nivel mundial.

- Implementan formatos y desarrollan contenidos que generan audiencia "masiva" local: para hacer frente a la dinámica hegemónica de los medios masivos comerciales, los alter comunicadores crean permanentemente nuevas-otras estrategias de producción mediática. Existe en estos alter medios 
una re-creación permanente de los formatos y los géneros periodísticos e informativos. Estos nuevos-otros formatos y géneros atienden los contextos y las realidades de las comunidades de referencia, reconociendo los lenguajes propios, las formas particulares de narrar, los temas prioritarios de comunidades y territorios. 